\title{
The Bottom-Up Development Model as a Governance Instrument for the Rural Areas. The Cases of Four Local Action Groups (LAGs) in the United Kingdom and in Italy
}

\author{
Giuseppe Gargano
}

Citation: Gargano, G. The Bottom-Up Development Model as a Governance Instrument for the Rural Areas. The Cases of Four Local Action Groups (LAGs) in the United Kingdom and in Italy. Sustainability 2021, 13, 9123. https://doi.org/ $10.3390 /$ su13169123

Academic Editor: Dalia Štreimikienè

Received: 17 June 2021

Accepted: 12 August 2021

Published: 14 August 2021

Publisher's Note: MDPI stays neutral with regard to jurisdictional claims in published maps and institutional affiliations.

Copyright: (C) 2021 by the author. Licensee MDPI, Basel, Switzerland. This article is an open access article distributed under the terms and conditions of the Creative Commons Attribution (CC BY) license (https:// creativecommons.org/licenses/by/ $4.0 /)$.
Research Centre for Agricultural Policies and Bio-Economy, Council for Agricultural Research and Economics, Via Po, 14, 00198 Rome, Italy; giuseppe.gargano@crea.gov.it

\begin{abstract}
The present research which originates from the author's PhD dissertation awarded at the School of Politics of the University of Newcastle upon Tyne in 2019, explores the comparative evolution of rural development policies and Local Action Groups (LAGs) in the United Kingdom (Argyll and the Islands LAG—Scotland and Coast, Wolds, Wetlands and Waterways LAG-England) and in Italy (Delta 2000 LAG_Emilia-Romagna Region and Capo Santa Maria di Leuca LAG_Puglia Region) in a multi-level governance framework. LAGs and in particular their public-private local partnerships have become common practice in the governance of rural areas. This governance operates within the European Union LEADER approach as a tool designed to generate the development of rural areas at local level. In order to establish the implications of the LAG practices, the following main objectives for this research have been established: (1) to explore the utility of EU strategies for rural development; (2) to explain how LAGs structure, institutional arrangements and working are positioned in the layers of MLG framework; (3) to carry out a comparative evaluation of the LAGs working in the different nations and their subnational contexts. Some significant findings from the case studies are summarized in relation to these themes: the key characteristics and the outcomes associated with the LAG working mechanisms and what do we draw about the emergence, operation and performance of local partnerships. The core argument of the research is that the partnership approach has given the rural development actors a governance platform to help increase beneficial interactions and economic activity in each of these LAGs, but it is the bottom-up leadership of key local actors, seizing opportunities provided by the EU funding, which have been the most important factors for the LAG successes.
\end{abstract}

Keywords: rural development and cohesion policies for rural areas; community-led local development partnerships; multi-level governance

\section{Introduction}

Since the late 1990s, the importance of promoting integrated rural development in Europe, with a strong emphasis on local solutions for local problems, has been widely acknowledged. National institutions cannot solve rural development problems alone. This has led to the formation of partnerships that see cooperation between the public and private sectors so they can contribute to the implementation of rural development policies at various levels, supplementing decisions taken by national parliaments and local elected councils. The impetus for working in partnership has been given at European Union and national level as a participative approach to create and implement local development strategies to which financial resources are allocated [1]. Through this governance framework centered around the local partnership process, the rural development issues (such as the agricultural industry, economic diversity, land-use practices and social inclusion) are considered in a more effective manner when compared to that offered through the coordination of direct government [2]. 
The present research explores the comparative evolution of rural development policies in the United Kingdom and Italy using a multi-level governance framework. It highlights the increasing importance of a bottom-up development approach and allows us to explore governance issues of how this process can benefit both the policy making and the rural development outcomes. More specifically, it draws on the experience of four public private partnerships in order to understand the conditions, including political arrangements and actors, that facilitate or hinder their development and their workings, and it evaluates the added value that flows from the bottom-up approach to local development process of the areas they serve compared to the more conventional way.

The main assumption is that rural support measures become more effective if decision making and implementation are locally embedded. Therefore, when correctly applied, the bottom-up approach can lead to added value because of a better identification of local needs and solutions, more commitment of stakeholders and a greater scope of innovation which manifests itself in

- improved social and human capital which includes features of social organizations such a build-up of the local identity, development of new skills and capacities that facilitate coordination and cooperation for mutual benefit and make the community more resilient and adaptive to changes;

- improved local and multi-level governance in the implementation of the strategy which comprises participatory decision making, through which public, economic and civil society stakeholders as well as local people, articulate their interests, exercise their legal rights and mediate their differences in a collaborative manner;

Nevertheless, the assumed added value of the bottom-up approach has not been convincingly demonstrated so far as well as challenges and examples of added value are not only strictly connected to one individual form. The diverse and scattered evidence might partly be due to the context dependence of implementation and success of rural development policies at local level [3].

In this context, the European Union LEADER approach (Liaison entre action de développement de l'économie rurale-Links between actions for the development of the rural economy) is a tool designed to generate the development of rural areas at local level. The approach does this through Local Action Groups (LAGs) and in particular their local partnerships "who are assumed to share a common degree of commitment to specific policy objectives at a strategic level to specific policy objectives, at a strategic or delivery level" [4] (p. 75). Three types of members from the various sectors are defined by the EU policy: the public sector is represented by the local authorities' representatives having a mandate from local elections, the private sector is represented by the agriculture, handicraft, tourism and enterprises trade associations and the third sector which is represented by the associations working in the field of rural development and community regeneration. They operate within a structure and are responsible for devising and implementing development strategies for their areas by gathering consensus, openness and local people invitation to participate.

Although the focus is on local level partnerships, this LEADER governance system is also partly a result of a 'top-down' process where EU and member states' institutions impose the partnership model as a mandatory requirement for funding the local development projects [5]. The concept of participation is connected to partnership working, which is presented by academics, politicians, policy makers and practitioners as inherent and imperative to the preparation and implementation of EU rural development policies. However, there still exists a limited understanding and knowledge about how the partnerships work in practice, the perceived benefits and project planning. Despite the generation of many studies on rural partnerships, relatively few have focused on their processes as the impact of rural policies depends not only on the local context of a rural area but also on the logic of how the partnership works [6]. Furthermore, the formal assessments of the funding programme implementation do not refer to those wider governance dynamics arising from the application of these approaches as the assessments continue to focus on examining the financial management system and measuring project outputs. 
According to Lowden and Sullivan [7], for example, partnership can be a "means" for seeking the view of citizens on particular topics while participation can be an "outcome" for the mobilization of the communities and an "ingredient" of the partnership working. These dynamics can occur because the stakeholders, organizations and citizens including communities and elected councilors are the key partners that work together on a range of issues.

Important questions arise about who participates and how the partnership works as a governance instrument at the interface of state and society.

"Participation, then, necessarily takes place through representation and the possibilities for empowerment and getting one's voice heard are then dependent on the quality of representation. Therefore, participation and representation are interconnected notions that are both relevant to the study of partnerships" [8] (p. 77).

Although researchers have carried out studies of these partnerships in EU states, there have been no detailed empirical and comparative studies of their specific nature and context since 2001. As this was an under-researched area, the article aims to fill in this research gap in the literature, to provide some original empirical research and to aim to update the comparative analysis and outputs of the PRIDE Research Project (Partnerships for Rural Integrated Development in Europe) [1-10]. This project was carried out during the period 1999-2001 and brought together researchers to establish what was known about rural development partnerships in eight EU countries (United Kingdom, Finland, Germany, Italy, Spain, Sweden, Ireland, Luxembourg) in order to identify the key aspects of their emergence, organization, management and performance. The study represents a pioneering attempt to evaluate the role of partnerships. The research findings provided evidence of the European and national policies' role in establishing partnerships for rural development and highlights similarities and differences of the political-economic and institutional contexts between the eight countries. However, according to Larner [11] (p. 377),

" $(t)$ he weakness of the PRIDE research programme ... is the apparent lack of theoretical framework that would generate more rigorous analysis of the empirical research findings ... The PRIDE research programme clearly has the potential to make a major contribution to the rapidly growing academic and policy literature on partnerships, however the analytical work required to distil and highlight this research contribution has not yet been done."

According to Bristow [12] (p. 88), "there is no reference to the concept of governance ... in terms of capturing the systemic interconnectedness among government, civil society and the modes of political and economic coordination."

Therefore, the present research, using the Multi-Level Governance framework (MLG), conducts a comparative analysis of the experience of four EU LEADER LAGs/public private partnerships operating in the UK (Argyll and the Islands LAG-Scotland and Coast, Wolds, Wetlands and Waterways LAG_England) and in Italy (Delta 2000 LAGEmilia-Romagna Region and Capo Santa Maria di Leuca LAG-Puglia Region) in order to understand the conditions, including political arrangements and actors, that facilitate the development of the partnerships and their operation during the 2007-2013 programming period. Although the existence of EU guidance on rural partnerships creation means that the LAGs exhibit many similar characteristics, each LAG has its own history and specific way to approach local partnership working. This is due to the national and local context, particularly in relation to the political and the local management structures and the power distribution within the local government [13]. The ability of the actors to affect the policy making processes varies as a consequence of factors, such as the existing cultural values, institutionalized policy practices, ideas and finally the regulations to be implemented. Even if local actors' involvement was designed to enhance democracy, and although a number of countries have decentralized authority to a lower tier, the empirical findings suggest that, in some member states, the central institutions continue to preserve their influence 
and shape outcomes [14]. LAGs governance can be considered as the pooling of resources in terms of local interest to face economic and social challenges within the rural area.

Thus, given the limited knowledge about local partnerships working in rural development and the characteristics of local partnership practice and capability to deliver rural development, this research has the aim to fill this gap through a comparative analysis, providing a detailed exploratory study focusing on the longitudinal observation of case studies.

\section{The Multi-Level Governance Framework}

Multi-Level Governance (MLG) is one of the few theoretical approaches to analyze the EU integration processes that can be considered as appropriate for understanding the LEADER approach; the other integration theories tend to not to emphasize the relevance of the sub-national and the local level [15]. Initially intended to analyze the multiple levels and actor interactions within the EU Regional Policy, research on MLG has been extended to study a great number of additional fields such as economic, environmental and mainly rural development, the latter being largely absent from the debates in the context of European integration studies.

Gary Marks [16], who was one of the pioneers in conceptualizing multilevel governance within the EU and on Structural Funds implementation, demonstrated that a variety of levels are involved and that there is no uniformity among the states as to the involvement of these subnational actors in European integration. Marks argued,

"subnational actors were increasingly influential in decision-making, so EC decisionmaking could be described as multi-level whereas previously only two territorial levelsnational and supranational — had been deemed worthy of serious analysis in the debate between neofunctionalists and intergovernmentalists" [16] (p. 3).

Thus, the debates concerning European integration understanding missed the increasing importance of sub-national levels in the decision making process and their connections with other levels.

Marks [17] (p. 392) puts forward his theory of multilevel governance

"as a system of continuous negotiating among nested governments at several territorial tiers-supranational, national, regional, local一as a result of a broad process of institutional creation and decisional reallocation that has pulled some previously centralized functions of the state up to the supranational level and some down to the local regional level".

These tiers interact with each other

"at different administrative and territorial levels: (i) across different ministries and/or public agencies at the central government level (upper horizontally), (ii) between different layers of government at local, regional, national and supranational levels (vertically) and (iii) across different actors at subnational level (lower horizontally)" [18] (p. 13).

The point of departure is the following: the presence of overlapping competencies, the interaction of political actors among multiple levels of governments and the member state not acting as the exclusive link between domestic politics and EU level [19]. Marks argued [20] that EU Structural Funds and the Cohesion policy of the 1980s and 1990s provided evidence that central governments were losing control to the European Commission which played a fundamental role in designing and implementing the funds and to the regional and local governments of each member state which were granted a partnership role.

Thus, it is not just member states involved in implementing EU regulations but also local administrations operating under the influence of the EU. Neglecting the inclusion of the local level in the framework of European integration theories means excluding an important and vital level of governance within the European Union.

Local authorities have responsibilities in implementing programmes, and in several member states they act as managing authorities of the funds. Decentralization of power to 
sub-national and local levels in implementing the Structural Funds improves the resource management of the community participation as it has the advantage that local actors know the local needs much better than others for the development of their local areas [21].

In addition, governance at this level involves not only public administration but also representatives from the private sector such as economic and social representatives. These actors come from different backgrounds, originate from different levels, share competencies, are dependent on each other and are organized or try to exert influence on three levels of administration: supranational, national and sub-national.

Being the lowest level of the EU, it is the closest to the local residents and enables them to have access to and to participate in policy making processes and interact with governmental institutions at all levels and has also the potential to make the EU visible at the local level and to the local residents that have access to policy making [22].

Understanding these processes is particularly relevant as part of the new governance. These processes are adapted by people as they are influenced by the cultures and traditions in which they live and are dominated by market relations and policy makers seeking to alleviate the resulting social and economic inequalities.

Hooghe and Marks argue [23] that understanding of the dynamics of decision making is necessary to consider how different jurisdictions interact with each other. Such an analysis is essential for explaining what characterizes these relationships in terms of hierarchy, interdependence, or relative independence and if they are general-purpose or specialized, mutually exclusive or overlapping. They theorized the unravelling of the state [24] and the emergence of a new pattern of relations between different government levels that were traditionally hierarchically ordered and are now challenging these established relations. In addition to the classical multi-level structure of legitimized institutions situated at EU, national and local level, "new forms of governance that is, formal and informal networks or functional units of cooperation have been set up to foster efficiency and democracy" [25] (p. 2). In sum, whilst the EU institution at supranational level, the member state at national level and all sub-national levels are composed of stable forms of governance, the $\mathrm{EU}$ is also characterized by an increase in functional structures created to solve specific policy problems.

More specifically, in an attempt to define the theoretical space within which the intergovernmental relations emerge in the EU cohesion policy, Hooghe and Marks [24] label two types of MLG: Type-I MLG and Type-II MLG.

Type-I MLG regards general-purpose jurisdictions-international, national, regional, local-between a limited number of government levels over a given territory or a set of issues. Under this type, the jurisdictions are divided into units, each with separate and independent powers and policy responsibilities. The structure is divided into an executive, an elected legislature with representative institutions and a judiciary with a court system. This idea is especially strong in Europe where local government usually "exercises a wide spread of functions, reflecting the concept of general-purpose local authorities exercising comprehensive care for their communities" [26] (p. 26). In this form of governance, there is only one relevant jurisdiction, which is intended to be stable for periods of several decades. To exemplify general-purpose jurisdiction in Type-I MLG, one might look at the stable structures of the municipalities, which are responsible for a variety of different tasks, such as social policy, local planning or environmental protection.

Type-II MLG is distinctly different. The jurisdictions are task specific and are intended to be flexible to respond to changing functional requirements rather than durable ones [24]. Jurisdictions are fragmented into functionally specific units and provide particular public services at local level, such as police, fire protection, welfare and health and transportation. Each public service has a jurisdiction which internalizes its benefits and costs. In this type, there is no predominant class of actors but a wide variety of public and private actors sharing the same geographical space and a common need to take collective decisions or to solve coordination problems. Individuals relate to jurisdictions such as professionals, farmers, homeowners, nature lovers, shoppers and so forth. Jurisdictions may be created, 
adjusted or deleted when these jurisdictions no longer serve the stakeholders' needs, through inter-jurisdictional competition for citizens' participation or dues.

A prime example of a task-specific jurisdiction in Type-II MLG would be the LAGs engaged in LEADER approach at the local level to deal with particular policy tasks and to receive EU funds.

"These groups include a variety of public, private and social actors and membership is open. In contrast, a municipality stretches over a certain geographical area and is non-intersecting as regards other levels of governance. Another important difference is the constitutional structure. In contrast to Type-I MLG, Type-II has neither a legislative nor a judicative body" [14] (p. 29).

Moreover, Type-I jurisdictions bundle decision making at a few levels as they are at the heart of democratic elections, legislatures and executives, and they support a class of professional politicians that mediate citizen preferences into law. In contrast, TypeII jurisdictions are set up to solve policy problems, such as managing a common pool resource, and setting a technical standard. A Type-II MLG can be economically more effective with problem solving taking place at the very level of concern; it is also more adaptive in response to changing preferences and open to innovation and it is closer to people and, at least theoretically, offers space for them to participate.

According to Bache et al. [27], in Type-I jurisdictions there are some deficits that have negative effects on legitimacy and democracy in terms of incomplete information, coordination among decision making jurisdictions and networks, policy formulation and decision blocking by higher level administrations. For instance, concerning information, not all actors such as municipalities in EU regional policy, who should have the same starting position, are equally informed in order to be able to participate. This is not only due to information deficits, but also due to their lack of financial and human resources.

Indeed, they hypothesize that, although local actors from different levels are expected to participate in policy making in Type-II jurisdictions, not all of them are included in the process of decision making. The inclusion of individuals at the local level, however, can take place during the input phase of policy making that is the formulation about the local strategies and even more during the implementation phase when the concrete realization of certain projects by functional units such as LAGs are open to individuals' participation. Thus, in the case of EU funded programmes and more specifically in the case of LEADER approach implementation, this means that $\mathrm{EU}$ can be more easily and directly experienced by its citizens. This is not only in terms of participatory forms of democracy but also, and probably more importantly, in terms of legitimizing the functions of EU institutions and public-private interaction which brought concrete results to the local level [28].

Finally, Type-II MLG jurisdictions borrow some of the legitimacy, consensus and accountability mechanisms from Type-I jurisdictions: they also attempt to create mechanisms of their own. Type-I MLG jurisdictions legitimacy derives from the procedures by which they are regulated such as roles and norms while the legitimacy of Type-II MLG jurisdictions depends on their effectiveness and the competences of their management. According to Pierre and Peters [29], these two types of governance are in a "negotiated order" where the institutional level, in this case the European Union, tries to get these newer forms of governance inserted into a context, which is still dominated by existing institutions.

While the MLG is the first EU integration theory approach which analyzes the position of actors at local level, another approach, Structural Constructivism, has been more sensitive to some of these issues as it helps to explain the EU mechanisms and players framework in the daily interaction and the potential power of actors in the construction of the political space [30]. Although this research does not use Structural Constructivism in the analysis, the approach does provide some useful warnings about the limitations of MLG that this article acknowledges.

For reflecting on how individuals perceive and interpret their position in a given field, Structural Constructivists collect data, engage in qualitative analyses of biographies, interviews and participant observation. 
At this level, while MLG is appropriate in analyzing the polity structure of the EU, member states and sub-national levels, Structural Constructivism makes a contribution by focusing on those structures in order to provide a better understanding of how they are constructed and by whom and where power is situated [31].

For Structural Constructivists, "European integration is a process which is driven and propelled by agents who are constrained by material and symbolic structures and who struggle to accumulate social resources" [31] (p. 777). This ontology is based on their interest not only in general characteristics but also in the bodies the agents are engaged in the constructing and reconstruction of institutions and policy making structures. MLG, in turn, has been blamed for being too vague, too technocratic in its selection and coverage of policy fields and for doing no more than describing recent developments. This can be readily understood when MLG presents EU as a "multi-level, non-hierarchical, deliberative and apolitical", being realized in a "complex web of public/private networks and quasi-autonomous executive agencies" [32] (p. 39). Structural Constructivism is not restricted to analyses of the EU multi-level structure or to analyses of supranational and intergovernmental actors and forms of policy making, nor is it limited to specific policies or national context [33].

With this thesis providing new empirical evidence from these policy fields, the picture the reader will receive on the position of sub-national actors in the multi-level EU polity is rather ambivalent. Even if the European Union has developed in a multi-level system of governance, there are actors that did and do benefit from the dynamic process of integration and new opportunities to participate. For others, the situation is often unsatisfactory. In that sense, studies on MLG could benefit from the application of the Structural Constructivism methodology as

"it is an additional and careful focus on individuals, on their feel for the game, their networks and strategies to utilize opportunities and their perception of their place in the institutional (multi-levelled) structures of governance all of which are key elements in the shaping of policy" [14] (p. 79).

The critique of Social Constructivism has been useful for conducting the empirical research and informing the analysis which relies on the MLG approach. Through the application in the research of qualitative techniques such as interviews and observation at meetings, some of the warnings found in the Structural Constructivist concerns will be used to better understand the decision making structures in the field of rural policy and to query where power lies.

It is possible to see why different approaches to policy implementation occur in different EU member states, even within policy fields such as rural development, which are under the label of the "Community Method" [20]. To highlight and to analyze these different and specific contexts, a strong effort was made to study the mechanisms that determine the distribution of the decision making, with the aim of addressing the gap left by the MLG framework and the other approaches interested in the study of the European integration and more specifically in the field of rural development at local level.

\section{Objectives and Research Questions}

In order to establish the implications of the LAG practices for rural development through a case study approach, the following main objectives for this research were established: (1) to explore the utility of EU strategies for rural development; (2) to explain how the LAG structure and the institutional arrangements are positioned in the layers of Multi-Level Governance framework when managing rural development; (3) to carry out a comparative evaluation of the LAGs working in the different nations and their subnational contexts.

With respect to this research, four key secondary questions were identified to achieve these aims and answer the primary research question. These are as follows: (1) what conclusions do we draw about the emergence and the composition of local partnerships? (2) What considerations do we draw about the outcomes and performance deriving from the LAGs working in rural development? (3) What is the added value of the LAGs that 
flows from the bottom-up and partnership approach to local development process of the areas they serve compared to the more conventional governance approaches?

The empirical research is concerned first with exploring the mechanisms employed and the processes involved in the practice of local partnership working.

The mechanisms and processes characterizing the partnership are deduced from the literature review, an examination of documents, the use of semi-structured open-ended interviews with a variety of key actors, and attendance at LAG meetings. Relying essentially on individual perceptions and written sources and given the issues that characterize the investigation of partnership practice (including for example such issues as "motivation", "representation", "mobilization" and "interaction"), the analysis of the material collected is predominantly of a qualitative nature.

In adopting this perspective, particular attention was given to a variety of issues including the context within which the practice is taking place, and the reasons, influences and factors that contributed to the initiation of the practice of local partnerships.

In addition, the empirical research is concerned with examining and describing the outcomes of the practice of local partnership, both expected and resultant, reflecting the views and attitudes of the partners involved.

\section{The Research Design}

The research selected the United Kingdom and Italy, which in recent decades have both witnessed a wide application of local partnership models for addressing rural development. The two states provide interesting, contrasting case studies because of their different institutional structures at sub-national level, their different traditions in relation to national policy making in the sphere of rural development, and their different approaches to and interactions with the EU policy making framework. These clear divergences make UK and Italy valuable case studies for the purposes of analyzing the practice of partnerships and how and why these succeed or fail in different institutional settings. Whilst evolving in two different environments due to their respective national context, interesting parallels can be drawn from the practice of partnership. Such a comparative examination is chosen as a means of establishing some general principles of local partnership practice within the context of rural development. In choosing to incorporate a UK-Italy comparison, it was taken into consideration the role and importance of the national, political institutional and cultural framework of each case country in the context of rural development and the way partnerships emerge, develop and are ruled as they "seem to reflect deep rooted traditions and cultures in the business of government and different histories of state formation" [34] (p. 487). Rural policies in both states are negotiated and delivered at a more decentralized level through partnerships that have some power over domestic and European funding for rural development management.

We can see that in the UK "there was a national rural policy, with the recognition of the need to better integrate the evolving regional and local dimension into rural policy and exploit the linkages between the environment and social economic activity" [35] (p. 199). This signified a series of important policy implications which were considered less in sectoral terms and more in socio-economic activities, a concern for people and communities in rural areas, an acknowledgement of the diversity of rural areas which reflects differing pressures and circumstances as well as distinct political and governmental structures. These implications are confirmed by a large number of studies on integrated rural development and on the impact or evaluation of partnerships as a form of governance which has moved away from national and local government administration across many policy communities and programme areas, and has incorporated a diverse range of quasi-government bodies and non-governmental organizations (NGOs). They have a long history, driven by longstanding frustrations with the fragmentation of rural government, notably the well-known division between land-use planning and resource planning.

In Italy there is no national rural development policy as it only derives from the EU agricultural policy and regional development framework. Previously, the problem of the 
development of disadvantaged areas, both rural and urban, characterized by the deep gap between the North, rich and industrialized, and the South, poor and rural, was addressed at the central level with a substantially uniform and a partially participatory approach for the definition of intervention priorities and the resource allocation. The approach operated without taking into account the diversity of the various territorial contexts. Italy does not have a solid tradition of partnership because until the late 1990s the policies for economic development were influenced by theories inspired by a top-down conception of governing. It was only with the diffusion of local development and the bottom-up approach that the practice of partnership became a feature of governance at local level. Therefore, Italy has a strong tradition of research into territorial development due to the presence of socio-economic differences between an industrialized North and a mainly agrarian South. However, there is not a specific tradition of studies on rural development and no systematic academic studies have been carried out on the implementation of the EU rural development policy with a focus on LEADER approach apart from the internal implementation and evaluation reports conducted by regional and national institutions.

Research and its theoretical elaboration on this issue has been developed only recently as a consequence of an increased interest following the reform of the EU rural development policies. By analyzing some publications on the topic, certain observations can be made about the Italian experience within LEADER and the working of its LAGs. Anyway, according to Osti [36] (p. 174) "it is not possible yet to generalize about the experience of development processes at local level ... as ... there is an indeterminacy in the models used to analyse LEADER and a slowness to elaborate new ones".

Concerning the political and administrative organization and the decentralization of power, the two counties show significant national similarities and differences. In terms of similarities, they integrated the government department by bringing together agriculture, environment and rural affairs and set arrangements to help rural stakeholders develop policy with central government. In terms of differences, in both countries there are National Strategic Plans (NSPs) which guide rural development policy. The UK NSP provides the basis for the Scotland Rural Development Programme (SRDP) and the Rural Development Programme for England (RDPE). The Italian NSP provides the basis for the regional Rural Development Programmes. However, even if the rural development policy implementation apparently does not differ, the lack of regions in Scotland and in England means that their relative rural policies are highly centralized compared to Italy.

In Scotland, although devolution granted a high autonomy in designing its rural policy, rural affairs are a matter overseen by the Scottish Parliament. "The problem is the integration of policies at local level, finding how they mutually reinforce each other or are in conflict ... that can also give feedback to the centre on possible improvements and new needs, adapt policy packages to local conditions" [37] (p. 92). This approach also makes it difficult to reconstruct after the fact of the rural policy's overall vision, in terms of budget expenditure and actions implemented in rural areas. In England, there are no formal intermediary government layers between national and local level representing an important issue for the delivery of rural development policy. In recent years, policy has been reshaped by a range of initiatives and has made great efforts in terms of reorganization of the governance, planning and policy assessment. In this context, Regional Development Agencies (RDAs), set up in 1999, played a central role in the delivery of rural policy and Government Offices as the representative of Whitehall in the regions, had the role of coordinating and influencing policy delivery and helping to join the center with localities. Therefore, the regionalization of the Rural Development Programme 2007-2013 for England meant that applications for LEADER funds were made to the RDAs as responsible bodies for negotiating with applicants and making decisions and becoming mature institutions with their own identity, experience of regeneration activity and autonomy to manage their resources. With the disappearance of RDAs, the Rural Development Programme of England is now delivered by DEFRA since 2011. Thus, the return to a national programme causes the removal 
of the former regional flexibilities that helped deliver approaches attuned to regional circumstances [38].

In the case of Italy, although the regions have been characterized by some degree of autonomy since the 1950s, it was only during the 1990s that a series of administrative and legislative reforms provided regional and local authorities with an increased autonomy. With the accelerating Europeanization of the rural development policy, devolution favored the Southern periphery in its entirety and local administration reached a higher accountability level which promoted a more effective use of EU cohesion and development funds. Even if the policy priorities are formulated at national level, the regions are responsible for the planning and implementation of the rural development programmes and the state, and its Ministry for Agricultural Policies has no constitutional legitimacy to take action in regional policy priorities. Regions implement rural development policies through a bottom-up development model that embraces the aspect of rurality in terms of territorial concentration, integration and concertation with partnership at local level [39].

However, while there are key differences in the British and Italian national and subnational institutional structures which mediate EU agricultural policies, at the level of the LAGs they share similar issues, arguments and expectations despite the different institutional, political and cultural contexts in which they emerge. This indicates that EU policies such as LEADER can help shape local governance structures.

The introduction of the LEADER approach "is said to mark the beginning of a new stage for the development of rural areas" [36] (p. 174). In the rationale behind LEADER, the European Commission places great emphasis on LAGs as a component of a vertical MLG setting in the following manner:

"The main concept behind the LEADER approach is that, given the diversity of European rural areas, development strategies are more effective and efficient if decided and implemented at local level by local actors, accompanied by clear and transparent procedures, the support of the relevant public administrations and the necessary technical assistance for the transfer of good practice" [40] (p. 8).

LEADER approach is giving some similarity in the approach to governance and therefore is building in MLG with respect to EU integration (at least in the area of rural development). LEADER is an approach which has been running for over 25 years and that it is important not only within rural development but also for its governance role that has been debated by policy makers and theorists over the last years. They described LEADER as a shift from government to governance aimed to decentralize central level to stakeholder platforms at local level. In contrast to the hierarchical bureaucracy of the traditional models of rural development LEADER aims to build capacity among the local population "to create public goods that will help to overcome the instances of market failure which characterize rural economies" [41] (p. 12).

This method is based on two principles: "decisions should be taken by bodies located as close as possible to the areas of intervention and the decision-making should involve all bodies on equal footing, be the fruit of long-standing reflection on development processes and based on the enhancement of local cultural identities" [36] (p. 172). LAGs can be seen as the local expressions of the shift from government to governance within EU rural development policy with the objective of enhancing their delivery at local level.

Even if the bottom-up approach is heavily emphasized in the literature, there is also the top-down component of the government in funding, planning and setting the rules at European and national level. From a comparison between the top-down and bottom-up development theories, it is clear that while in the former the subjects are institutional and the interests are exogenous, in the second the subjects are local and the interests are endogenous whereby the LAGs are dealing with their LDSs and make decisions about projects that are implemented by the beneficiaries. The case studies research showed that the rural development partnerships share common issues and similar trajectories of development, but the context, rural issues, developmental challenges and institutional structures clearly differ. 
Consequently, while it is important to consider the national political and institutional context in relation to partnerships, it is also necessary to go beyond contrasts and parallels and to concentrate on their internal dynamics. The empirical investigation therefore consists of LAG case studies.

The four case studies represent some of the diversity of the LEADER implementation through public-private partnerships, but they are not representative of all LAGs operating in the countries/regions to which they belong. As the practice of LAGs concerns a wide variety of local areas involved in rural development action, it was decided to identify two representative LAGs (one LAG in a marginal region and one LAG in a more prosperous one) in each country according to the official data of their Rural Development Programmes 2007-2013. The selection of the LAG case studies used the following criteria: the examples had to present an active history of public and private initiatives, were well established partnerships and involved clear evidence of action on the area they serve. They are examples that are promoted by their residents and the local authorities as best practice at European, national and local level.

Hence, in a search for a case study in the UK and following the abovementioned criteria, a prosperous region was selected as a case study: the Yorkshire area of England and the practice of the Coast, Wolds, Wetlands and Waterways (CWWW) LAG [42]. It was chosen as a case study in a marginal region: the south-west of Scotland and the practice of the Argyll and the Islands LAG [43]. They both showed evidence of an active history of rural development initiatives and partnership working experiences.

Concerning Italy, the Emilia-Romagna region is considered by the EU Commission as the "textbook case-study" for LEADER, regarding innovation and involvement of private actors, pursuing in its policies both objectives of development and social cohesion [44]. The region has a history of cooperative movements which are at the base of the so-called 'Modello Emilia' (Emilia Model) a model of "endogenous development" and "local development" which reflects a strong multi-level governance system with devolution of planning and implementation activities to provinces according to the regional law no. 15/97 [45].

As the second Italian case study, the marginal area of Puglia region distinguishes itself by being one of the most advanced southern Italian regions in implementing a bottom-up development model that embraces the broader aspect of rurality in terms of concertation with the different local government levels, the socioeconomic actors and government and institutions.

In these different contexts, the Delta 2000 LAG in Emilia-Romagna and Capo Santa Maria di Leuca LAG in Puglia represent successful implementation experiences of the LEADER approach because they succeeded in stimulating self-governance processes by involving the local population, the private operators and the local authorities along with higher institutional levels.

In adopting the case study approach, particular attention was given to a variety of issues including: the reasons and factors attributed to the initiation of the partnership, the organization and management of the local partnership practice, the partners and their motivation and involvement, the difficulties and constraints, their workings and the added value to the development of the rural areas they serve. The cases allowed a focused comparison of the rural areas in terms of similarities and differences and involve isolating key elements, common points and differences, as well as the evaluation of the European, national and local level politics.

Some significant findings from the case studies are summarized in relation to these themes: the outcomes, achievements and benefits that could be attributed to the local partnerships working in rural development and what constitutes the limits to the local partnership practice to achieve the objectives of their local development strategies.

To understand the framework of policies, official documents from the EU, national institutions, local authorities, and LAGs were collected and analyzed. As these official documents are usually the final versions of policies or programmes, the process of transformation through which initial ideas were adapted is often unpublished. To find this missing 
information before and after the official documents were published, internal reports and minutes of meetings were gathered during the fieldwork. The documentary analysis covered all four regions of the case studies and provided a historical context in a rapidly changing policy environment and insight for discovering future plans.

Interviews form the cornerstone of the research. Face to face, open-ended interviews were more suitable than a questionnaire approach as they allowed to investigate the interviewees' experience and opinion in depth. In order to identify the key individuals within the LAG, the preliminary information was used such as the documentation already collected and the early contacts with the LAG managers. Then, the key interviewees were identified on the basis that they represented a sector or a group in the rural policy field and on the varying roles and responsibilities they had in the LAG and that could help answer the research questions. A snowballing method was used in which a few appropriate individuals were asked to recommend other people who would be useful to speak to; they even helped to make contact, which was one way of overcoming issues of gaining access to key interviewees. Such people were identified among the partners themselves, staff members, employed persons in local associations, trade unions and in the local administration, local entrepreneurs involved as beneficiaries of the partnerships' activities, other possible privileged witnesses and responsible persons involved in the partnership policies definition and implementation. At least six face-to-face interviews were conducted in each case study, beginning with those who were directly involved in the partnership initiation and workings.

The interviews took place in the UK (Argyll and the Islands LAG and CWWW LAG) in December 2013 and in Italy (Delta 2000 LAG and Capo S. M. di Leuca LAG) in July 2014 at the time when the LEADER approach 2007-2013 programming period and its activities were about to end and the new 2014-2020 programming period was about to begin. The interviews were conducted in a semi-structured way by using a list of topics and key questions suitable for use both in the UK and in Italy to provide a basic list of common topics and designed to explore a wide range of relevant issues. To this end, the choice of the questions reflected the objectives of the research, the findings of the literature review and the data included in the preliminary explorations of the documents and related to the following key issues affecting the case study: the reasons of the emergence of the partnership and what were the expectations and perceptions underpinning the partnership; partnership composition, organization and operation, the decision making processes; main objectives, activities and achievements of the partnership; assessment/reflections, general conclusions and confidential information of the main key strengths, opportunities and weaknesses of the partnerships, the outcomes associated in terms of business supported, jobs created, service provided.

A series of informal partnership meetings were also attended. The objective in attending the partnership meetings was to observe aspects of local partnership operation, particularly the interaction between partners, partners' roles and the decision making processes and implementation of policies, strategies and projects [46]. It was expected to attend a large number of meetings; however, only one meeting per LAG occurred at the time of the fieldwork in either case study. They were the last ones because the 2007-2013 programming period was drawing to close. Nevertheless, the observation of the last meetings still gave an insight into the decision making process and how individual actors and organizations interrelated within the partnership.

After the transcription of the interviews and the notes taken after the observation at meetings, the process of elaborating the narratives began.

Four thematic areas were inductively identified as the fieldwork progressed and for each a set of analytical paragraphs was elaborated to aid the writing up. They were description of the LAG area and its rural development strategy; origin and composition of the partnership; organization, operation and involvement; objectives, outcomes, achievements of the local partnership practice. 


\section{The Implementation of EU Rural Development Policy in the UK}

In the UK,

"prior to devolution, regions and local areas were able to articulate their own strategies and the mix of policies that best fit their strengths and weaknesses as well as negotiate the necessary funding within the Structural Funds. Devolution coupled with the framework created by Agenda 2000, significantly changed the governance of rural policy. The transparency of the planning process increased with devolution since the consultation of individual stakeholders was extended considerably" [37] (p. 104).

Decisions about policy design remained at central level. In 2001, the central government created the first Department of for Environment, Food and Rural Affairs (DEFRA) with agricultural, fisheries, rural and environmental responsibilities.

In Scotland, with devolution, rural affairs became a matter overseen by the Scottish Parliament and the Scottish Rural Development Programme 2007-2013 (SRDP) could be viewed as the delivery plan for Scotland's rural policy which remained highly centralized with little sub-regional delivery infrastructure. Decisions about policy design remained at national level where the Scottish Executive Department works with DEFRA to ensure that Scottish issues are represented. In addition, for the preparation of the SRDP the Scottish Rural Development Programme Stakeholder Group was created which is a network of specific stakeholder rural groups such as LAGs, Unions, Rural Estates and Council Voluntary Organizations.

The OECD [37] reported that even if Scotland's rural policy was innovative and rapidly evolving, it needs to recognize the differences between rural areas in terms of approaches at sectoral and territorial level and through the development of linkages between farmers and the wider rural economy. In this system there is a loss of empowerment by the local and regional level. Local actors, without a recognition of their multiplicity, adapt to top-down strategies to get resources even if that does not correspond to the needs of their territory. Therefore, Scottish rural policy is considered to be too centralized and that, although devolution granted Scotland a high autonomy in designing its rural policy, the Scottish Government needs to look at the development of some kind of regional body to improve the devolution of policy delivery and to involve a set of stakeholders in policy design and implementation.

In England, in response to finding that rural delivery structures were bureaucratic and too centralized to meet new challenges, DEFRA developed the Rural Strategy 2004 [47]. The strategy confirmed the merit of decentralization. Government offices should coordinate rural partnership processes and monitor rural delivery, while RDAs were given the responsibility for managing the funding of rural programmes [35].

Devolution of the Rural Development Programme for England (RDPE) funds to the RDAs resulted in a significant shift, which enabled the EU and national plans to be interpreted differently in each region. According to Ward and Lowe [47], even though the role of the RDAs in rural development was a key element, the regionalization of rurality had, prior to the abolition of the RDAs, not achieved a real development in England. This was due to the lack of tradition of regional administrative decentralization and the devolution which raised the need for the agricultural ministry of England to consolidate the new devolved executives. During 2005/2006 the RDAs began to prepare regional plans showing how they would implement the socio-economic measures of the national rural development programmes and creating the administrative bureaucracy. Moreover, there was a considerable mismatch between the role of the top-down decision making level RDAs and the LEADER approach of the bottom-up decision making LAGs. On one hand, the LAGs are the application of small amounts of financial resources to projects with an integrated impact on rural areas [48]. RDAs needed to understand the local problems to get relevant information on socio-economic trends in order to shape their own strategies and to appreciate the added value of their own interventions such as farm diversification activities. 
The OECD reported [38] that its multi-sectoral approach to rural policy needs to be improved in terms of impact at the policy design stage as well as delivery, for the remote rural areas as it did for those closer to cities. The impression is that the center remains solely responsible for designing policies and the creation of a bottom-up development approach could be difficult in the absence of strong efforts to invest in local actors and to provide them with adequate means to implement a long-term strategy. Moreover, the ability of local communities to act independently is constrained by national planning directives and mainly by the absence of a tradition of strong local government. It is difficult to agree on rural development strategies in a context of different central and local government levels and a challenge to identify and establish priorities to intervene where the institutional agenda prevails and where the interaction among different levels of authority is poorly developed.

\subsection{The History of the LEADER Approach}

LEADER approach in the UK, as in the rest of the EU, included four programming periods: LEADER I (1991-1993) an innovative and relatively small programme of short duration with minimal funds; LEADER II (1994-1999) which provided sustainable pilot projects; LEADER + (2000-2006) and LEADER as a mainstream within the Rural Development Programmes (2007-2013).

LEADER I targeted deprived areas-with the aim of improving their development potential on local initiative, promoting the acquisition of know-how and disseminating it to other rural areas. The programme was confined to all UK rural areas with GDP at $75 \%$ or less of EU average. These areas included the whole of Wales, Scotland, Northern Ireland and only Cornwall in England. The original intention of LEADER I was to help rural communities by engaging local partners in shaping the development of their area. It introduced the concept of local partnership with strong community representation alongside government, business and other stakeholders and was very much a pilot programme, which followed the same policy emphasis as the rest of the EU. Both in Scotland and England

"LEADER I marked the start of a new approach to rural development policy which was area based, integrated and participative. It was seen as an innovative tool for rural development given its ability to respond to old and new rural problems acting as a laboratory for building local capabilities and testing out new ways of meeting the social, economic and environmental needs of rural communities via a bottom-up' approach" [42] (p. 7).

LEADER II supported the principles of LEADER I and was designated to disseminate the successful approaches developed under the pilot programme more widely and to stimulate greater innovation and cooperation as stronger features in a more substantial programme of activity. New areas became eligible as it operated not just in deprived areas but also in rural areas with the status of Objective $5 b$ as the greater South West, Lincolnshire and other parts of eastern England, Northern Uplands in England and North and West Grampian, Upland Tayside, Rural Stirling, Scottish Borders and Dumfries and Galloway in Scotland. The approach was based on local capacity building with a focus on the opportunities for economic, environmental and social development and drawn from a menu of activities such as training, support for SMEs, rural tourism and basic services.

Although it built upon the two preceding programmes, the phase of LEADER + was available not just in the more deprived areas but in all rural areas and the LAGs were required to choose one or two topics to implement their local development strategies from a list of four: new technologies and new know-how; making best use of natural and cultural resources; adding value to local products; improving the quality of life in rural areas [48].

With respect to the former programming period, within LEADER + , the number of LAGs increased from 20 to 26 in England and decreased from 15 to 13 in Scotland. LAGs were required by the EU to be a partnership of local community, business, government, local organizations and stakeholder representatives of the area. In the decision making, 
LAG membership was to be balanced and to be able to represent effectively the interests of the different community and economic sectors in the local area. Local authorities could play a role to demonstrate that the plan and its implementation brings an empowerment of the local community.

When the LEADER Programme was replaced by the LEADER approach (as a part of the EU 2007-2013 rural development programming period), the LAGs changed in terms of geography across the regions and significantly increased in number to 20 in Scotland and 65 in England [49]. Some areas had operated a LAG during the previous programming periods. This was advantageous because the areas already had a managing structure and the know-how experience.

The key difference with the previous programmes is that the 2007-2013 LEADER approach is no longer a separate programme. It has now been "mainstreamed" as a delivery mechanism for the Rural Development Programme for England (RDPE) and the Scotland Rural Development Programme (SRDP).

DEFRA manages LEADER in England and is the managing authority of the RDPE, which has the role to ensure the respect of the requirements specified in the relevant EU regulations. DEFRA paid particular attention to local circumstances and priorities. In the first instance, this attention was exerted through the RDAs in order to reflect the strengths and weaknesses of their region in terms of LEADER expenditure, the size of the eligible areas, partnership arrangements with local authorities and others, and how LEADER contributes to meeting RDPE priorities at regional level to bring the regional spending and strategic priorities together with local communities. At local level, the agenda is expressed through the local development strategies of the LAGs which articulate the aims and objectives of the community and prioritize the types of project activities required in that area. Regional partners are encouraged to work with the LAGs to help build their capacity as well as to encourage strategies that address environmental as well as socio-economic objectives [49].

Concerning the LEADER management in Scotland, there is a direct link between the governing administration and the LAGs, as there is in all the other devolved nations. This is in contrast to England in which the RDAs had an intermediary management role between DEFRA at the top and the LAGs at the bottom in their regions. [50].

LEADER stakeholders stressed that the local spirit of LEADER should not be overwhelmed by government direction, but LAGs when implementing development projects should have freedom to consult locally, respond to issues at economic, social and environmental level. The real value of LEADER is that LAGs have the ability to set priorities locally in an autonomous way. These priorities are flexible to changes in local need, enabling LAGs to pilot new development approaches. It is also argued that LEADER's strength is in building capacity and networking among local actors [48].

Having laid out the declared benefits of the various versions of the LEADER programmes and approaches, we now examine what happens in practice.

\subsection{The Case Study of the Argyll and the Islands LAG in Scotland}

Argyll and the Islands is one of the 20 LAGs operating in Scotland; this LAG has its focus on a complex rural area which reaches from the Hebridean island of Tiree in the Atlantic west to the suburbs of Helensburgh in the east and from Appin in the north to the Island of Arran in the south. It has a land area of approximately 2852 square miles and a population of more than 83,000 people. Within 31 inhabited islands, the area presents significant challenges in terms of accessibility, integration and territorial development. Travel time is high, compared to other parts of the UK, due to coastlines, mountains, islands, single track roads and few transport links. Concerning the economy, even if the public sector is a major employer, the main activities are tourism, agriculture, forestry, fishing and aquaculture. For the 2007-2013 LEADER programming period, the LAG has a budget of GBP 21.8 million, including public and private sector matching funding. More specifically, convergence ERDF funding of GBP 15.8 million adds to LEADER funding of 
GBP 5.9 million. The overall aim of the Local Development Strategy (LDS) is to support sustainable community-based development of rural communities within the area [51].

The LAG strongly emphasizes community-led development alongside growing and supporting social enterprises and key sector-based enterprises, including agriculture and tourism. This is achieved by funding projects which contribute to revitalizing communities such as improving accessibility services for those living in the rural areas, supporting voluntary activity, enhancing the quality of life in rural areas, maintaining, improving and sustaining the important areas of natural, cultural and archaeological heritage; and to a progressive rural economy such as reducing the outmigration of active people, providing opportunities for economic growth, increased prosperity and productivity; supporting initiatives to encourage cooperation between the agricultural sector and other rural business sectors, building capacity and training, encouraging research and development [52].

\subsubsection{Origin and Composition of the Partnership}

The LAG Argyll and the Islands was initiated just prior to the start of the 2007-2013 rural development programming period. It was called this because it linked two regions through delivering mostly environmental projects. The two regions were Argyll and the Islands and Lochaber (the region neighboring Argyll to the north). The role of the Scottish government appeared be particularly important in the development of the partnership. However key individuals also played a major part, indicating the significance of local circumstances and personalities.

It is important to note that not everyone readily embraced this LAG approach. For instance, agricultural land use sectors felt they would not be eligible for LEADER because they are traditionally funded by other rural development measures. They believed that LEADER was not for them, so there was a common misunderstanding amongst farmers that the LEADER money was actually their money.

The members have the responsibility for delivering the LDS and making decisions on implementing LEADER, recognizing that the LAG has an important role for the communities of the area. It has the responsibility for awarding funding to successful applicants; its lead partner, the Argyll and Bute Council, is responsible for employing staff and managing the budget.

The LAG has 25 partner representatives from a wide range of public, private and community sector organizations where $49 \%$ of members are from the public sector and $51 \%$ from communities. There is a strong business community representation, including the Federation of Small business, the Argyll and Bute Agricultural Forum as well as the Highlands and Islands Enterprise (HIE) and the Argyll and Bute Social Enterprise Network (ABSEN) which helps to ensure that the LAG is able to bring the economic, innovative and business impact to the programme and where the private sector (e.g., SMEs) may be beneficial. There are also representations and organizations that represent their local communities, such as the biodiversity, the farming and forestry, the third sector, the tourism, environmental and cultural organizations. These sectors have been a key element in the creation of the local development strategy and play an active role in its management and delivery with a bottom-up approach and involvement of all partners which could help to select the most appropriate development themes.

The partnership's motivation for participation was the recognition that it did not have enough project skill to actually deliver to get more money from the European Union so LEADER became the obvious track. Most of the partnership are previous beneficiaries so they understand what the direct benefits are of participating. Therefore, they put their expertise into the partnership for the benefits of others. It mostly extended to coming along to meetings to decide on who gets what funding.

The people representing the private sector are not acting as individuals but rather representatives of their organizations and are also not politically elected members of other organizations on rural development bodies, but they have been selected for fundamental services. 


\subsubsection{Organization, Operation and Involvement}

Having representatives from different sectors all speaking and working together in one group allows for sharing of good information, knowledge and seeing integration.

The contributions which individual members make to their partnership divide between general functions shared by many partners such as to be an animator, to advise applicants, and identify gaps in rural development implementation, strategic planning, community representation. The LEADER strategy defines the term "animators" as any person responsible for building of good partnerships and ensuring the effectiveness of these partnerships, and so they are a vital part of the governance dynamic in the LAG.

In terms of responsibilities and roles within the rural areas, it is worth mentioning that quite a few of them have community development trusts. These trusts do an assessment of what they would like to see in the area of what needs to be upgraded, what they have and also done a fair bit of consultation with the local community and they will help support projects 'on the ground' backed by action plans, dissemination of information, network and involving the local community. Consequently, it is not just the LAG and then the community projects: there are various organizations in between that are there to assist in terms of community development [53]. This profile of membership appears therefore to be a long-standing feature of the rural governance rather than any significant development in the time period assessed for this case.

The LAG does not directly employ people. There are partnership agreements with the local authorities (e.g., the local council), which are delegated the responsibility and decisions to manage the contracts of the applicants.

The LAG reports to the partnership what they are funding and how it relates to the local development strategy and the community and makes sure that the priorities meet the priorities of the locally elected members. It gives out no more than 50\% (25\% LEADER + $25 \%$ Scottish funding) awards to a project. The applicant has to find the other $50 \%$ from a wide range of sources. The UK National Lottery is one such source although it is not administered by the government, but rather operates as a public fund and is available for anyone in the UK.

Concerning the involvement of the people in the partnership, the LAG disseminates information about the types of activities that they have funded so that the public can see. The public can get involved by applying to LEADER and getting direct feedback about their project. Community involvement and mobilization have been quite important for a lot of projects when they were initially thinking about them and also just deciding on the best type of structure or construction, whether this project can go ahead or not and with that level of support, to go not only with LEADER funding to build and to implement the project, but also to engage with other funders as well in match funding.

\subsubsection{Outcomes, Achievements and Added Value of the Local Partnership Practice}

In terms of outcomes reflecting the diverse nature of integrated rural development projects, a significantly raised awareness of local issues and an increased level of community involvement are at the top of the list.

The interviewees recounted that the biggest outcome of the LAG activity is a developing coherent regional scale to key economic sectors in terms of creating jobs, funding new social enterprise, put in capital and infrastructure projects such as significant village halls and community buildings improvements such as social and sporting facilities. These buildings are very much multipurpose use and they are designed to be not just an area for people to gather; there are various facilities for activities such as sport, meeting rooms, lecture rooms, day and evening classes, adult learning, clubs for the younger people and lunch or afternoon tea clubs for the older people. The LAG approach is to induce people to use these facilities as a community center rather than a private village hall and where a lot of people are getting paid in terms of providing services.

A further successful example was the Healthy Initiatives project concerning a provision of support through LEADER to employ additional staff for primary health care 
for unfit people and with health problems. Another successful type of project was that of providing training for young people that would otherwise have found it very difficult to find employment and to give them skills in rural areas and maybe develop their own businesses from that start that was given to them under LEADER.

The tourism sector did not have a representative body before the LEADER programme to develop the tourism economy; this was equally the case with agriculture and land management where the actors did not have a land management body to focus on local needs.

Over recent years there has been a push towards marketing Argyll food. Before, quantities of food from Argyll were being sold, without a label, and were being moved from one side of the country to the other and then being re-labeled. These foodstuffs would include things like Tyree lamb, beef products, as well as cheese. Now, there is a lot there that can be marketed as food from Argyll and there is a group of various producers that have been going to various festivals around the country and being part of a food hub, supplying food to the great and the good. Moreover, local restaurants and even in the local schools, thanks to a LAG pilot initiative to supply local meat products and vegetables, are actually getting these, reducing the food miles of what they consume.

In terms of added value, the LAG works as a means to bring not only LEADER but also transitional funding such as European Regional Development Fund (ERDF) and European Fisheries Funding (EFF) into Argyll. A further overarching success is that it still operates as a co-operative and effective partnership, and that it is the norm rather than the exception for delivering development objectives at social, economic and environmental level in the rural areas. The LAG implements governance that allows appropriate spending of European money in the area which could have been misspent.

With this assertion it emerges that what counts for the development of rural areas is the need for local community support not just to legitimize the partnership working but also to provide valuable local knowledge, skills and commitments. The interviewees claimed that there will always be a need for constant engagement and outreach to local communities because there will be some communities in Argyll that will be untouched and that need to develop themselves. For these communities, if they do not have funds in place, the idea would not even come off the drawing board.

Funding is indeed an important issue both for the LAG working and for its successful continuation. However, funding mechanisms can also create severe difficulties due to inflexibility and excessive bureaucracy which is perceived by the project applicants because they have a lot of compliance monitoring and paper work to do and the LAG administrative structures are expending a lot of effort on this in their spare time as they do not have a full time job as LAG administrators.

Here there is a real dichotomy between LEADER being about innovation and rural development on the one hand, and, on the other hand, every decision being scrutinized by an audit because it looks as if it might fail and dampen the willingness to take risks. It does mean that people limit their actions to some extent on the ground because they are frightened of trying something that might be deemed ineligible and that might mean that they could have their money taken off through the auditing process. Despite this limitation, the LAG gives the opportunity to be more creative with the way they fund projects by spending more time in developing ideas and testing solutions before they fund an activity.

\subsection{The Case Study of the Coast, Wolds, Wetlands and Waterways LAG in England}

Coast, Wolds, Wetlands and Waterways (CWWW) is one of the 65 LAGs operating across England and is one of six LAGs which have their focus in Yorkshire and Humberside. The area covers approximately 880 square miles. The CWWW population of more than 150,000 people, puts the LAG at the very top end of scale nationally, considering that most LAGs cover a population of around 100,000 people. It includes 155 parishes and encompasses much of the East Riding of Yorkshire Council, excluding the towns of Bridlington and Goole as well as Beverly and its surrounding rural areas. In North Yorkshire, it includes the contiguous parts of Ryedale and Scarborough districts. Most of 
the land is of agricultural use. The area encompasses several different settlements, a range of economic and social characteristics and a variety of natural features. For the 2007-2013 programming period, CWWW had a budget of over GBP 2.8 million which increased to over GBP 7 million through other sources such as the Heritage Lottery Fund (funded through the UK National Lottery) and private donations. The overall rationale for its LDS development strategy is to link geographical areas of socio-economic deprivation with a broad contiguous area of environmental and socio-economic opportunity through a programme focused upon place-based rural development activity and to promote partnership working by bringing together organizations and individuals [54].

The LAG had a series of community consultation workshops throughout the area to all of the key partnerships and as a result of all of that they put together the local development strategy which identified key strands they needed to address and to develop. The related programme of activities was really about integrated sustainable rural development, but they focused largely on cultural heritage and tourism. There were some key projects that the LAG identified, and then, by reviewing each year what has been done, the LAG looked to see what the gaps were and targeted specific things to ensure that the projects achieved the key aims and objectives of the local development strategy. There was also a managed approach in terms of calls for projects; this involved articulating specific themes for the wider community to then apply for money to achieve.

\subsubsection{Origin and Composition of the Partnership}

CWWW follows on from the previous LEADER + Programme which operated exclusively across some parts of the East Riding Local Authority area. This former partnership was the direct result of the fact that East Riding of Yorkshire council had a rural strategy and policy. The decision to expand the area was taken for the 2007-2013 programming period in order to give a better functional landscape coherence to the LAG area and to introduce working across administrative boundaries for the benefit of the rural population living and working in the Yorkshire Wolds.

When the partnership was formed in 2007 to apply for LEADER funding, its members were drawn from a very broad range of the business community and statutory bodies to help deliver the local development strategy. They had a series of training workshops specifically for LAG members during the first year so that they could understand their roles and responsibilities and what was going to be achieved with the funding, the legal structure, the operating systems, the decision making process so that everybody was involved from day one, so there were not really any kinds of preconditions.

There was a specific fear on the part of partners from the new areas in North Yorkshire that they would not, in a sense, get 'a fair crack of the whip' or that they would be left behind in some way because they did not have the same degree of LEADER experience of the East Riding. Thus, it took a while for people to get over that and realize that this fear was not what was going to happen.

The membership includes representatives from public bodies (no more than $49 \%$ including Parish and Town Councils), private organizations and voluntary and community sectors. An inclusive approach was taken in the formation of the LAG, with the membership steered by appropriateness of the partnership in terms of private/public split, broad representation across social, environmental and economic interests relating the themes of the LDS and the capacity of members.

Basically, the LAG group has about 30 members from various different sectors, such as the National Farmers Union and the Driffield Agricultural Society that are the productive side of the rural economy, then archaeological groups and social groups. There is a mixture, a system of people interested in heritage, people interested in archaeology, people interested in just the social stuff, arts groups, churches and small economic and agricultural businesses.

There is a generalized feeling about the need for enhancing and preserving the environment and the cultural heritage on which they highly depend. Curiously, the partnership 
is not necessarily linked to the creation of employment with the promotion and development of local business but there may also be another important element such as the employment consolidation through grants to existing enterprises.

\subsubsection{Organization, Operation and Involvement}

The overall structure of the LAG consists of three main groups: the Local Action Group team (the main governing body), the Wider Local Action Group (the wider partnership, which information is communicated to), and the Decision-Making Board (a team of LAG members who specifically make decisions about the funding). There are also task groups to address specific issues if required.

The LAG team delivers support and guidance to potential applicants and beneficiaries to raise awareness of the themes of the programme, to build capacity to enable applicants to access funding, to develop control procedures in line with the funder and audit requirements, to develop and support community-based delivery partnerships, to regularly produce management information of progress towards the milestones and outputs of the programme.

In order for the LAG to be successful and perform to the highest of standards, the attendance and participation of members in various meetings, presentation and events is important. As the members of the LAG are voluntary, it is understandable that they have other work and family commitments that prevent them from attending the meetings. Thus, as it is not possible for all LAG members to attend every show, event, meeting, presentation, a monthly briefing note is circulated around the members, providing a summary of information on the progress and activity within the programme.

The concept of a Wider LAG (WLAG) was therefore developed because a number of people requested to be informed of the progress of the programme but did not want to attend meetings regularly. It works as a forum for discussion of major issues affecting rural development and regeneration across the area, to support the wider communications infrastructure of the LAG with reference to the communication strategy.

The Decision-Making Board (DMB) whose memberships consist of a maximum of 12 members out of which no more than five are from public sector bodies is responsible for approving applications for funding, commissioning projects to help develop opportunities for real economic growth and significant environmental enhancements, monitoring the progress of projects in terms of outputs and expenditure and to function as a discussion group to implement the LDS.

The opportunity to involve the wider local community not only in the process of drawing up the LDS but also in the implementation of the funded activities has been promoted by disseminating information in the press, the organization of public events which explain the role of the LAG, the aims of the strategy and where the involvement with the LAG at other levels was encouraged. There have been numerous meetings, events and road shows throughout the area to ensure that the widest possible opportunities for input and involvement were made available to local communities.

As a result of the awareness raising and consultation activity, other organizations made their contribution by proposing actions, as well as providing baseline data and the evidence of both the necessity and the benefit of work undertaken with village committees and community led plans.

\subsubsection{Outcomes, Achievements and Added Value of the Local Partnership Practice}

The implementation of the CWWW LDS contributed positively to rural development.

The key strengths are that the LAG is, as much as is possible, in contact with local communities and tries to keep in touch with the needs of the businesses and community organizations. This enables the LAG to help these organizations achieve some of their objectives, such as talking to people and trying to match up their aspirations with other people's aspirations and then build in some help, facilities and government or European 
funding, to enable that to happen. In terms of key outputs, they were not focused on jobs explicitly, but certainly did create employment opportunities [55].

The large geographical reach and high population threshold compared to many other LEADER areas in England has enabled the LAG to develop a wide and diverse range of interventions within the culture and heritage area. It has created a new understanding of the value of wildlife tourism in the local economy and has encouraged the formation of new partnerships such as the Yorkshire Wildlife Trust and the Yorkshire Water to promote and coordinate development together. The LDS has also given support and advice to businesses, created new employment and encouraged capital investments in wildlife reserves and accommodation and has raised the profile of Yorkshire in a European context, as a leading exponent of nature tourism.

Most of the projects have managed to increase community involvement and locality is proud of something that has happened. Therefore, for example, the cycle tourism, bed and breakfasts got increased business as they are now full of cyclists coming to the area. The same with horse riding and with nature tourism.

Therefore, in terms of achievements, the operation of the LDS has brought an awareness of valuable local resources, increased awareness of sources of funding and generated the recognition that key people, who are prepared to take an initiative, are the only that do something when there is a reasonably general agreement about it through decision making processes.

In terms of the capacity that has been built in some of the rural communities, heritage can be considered a very powerful tool in a sense that it is quite a dynamic mechanism for getting people involved in a community development context. There has been a major impact in bringing many more people together across the partnership area who have now learned skills in project management, project development and cooperative action. This has enabled the LDS to have a major "narrow and deep" impact in the area and the focus on heritage and culture has limited the effects of deadweight and displacement and has therefore delivered significant added value. There is also evidence to demonstrate that CWWW has delivered jobs and benefits to the environment and the communities in an effective, economic and efficient way.

By commissioning small feasibility work, the LAG has managed to triple that money by levering in a significant amount of other funding into the area. Where here they may have kick-started something small by providing some development money, they have been able to go on and lever in a lot of money from other places. Consequently, a GBP 2.8 million programme has ended up as a programme of currently GBP 7 million [55].

The networking activity has helped to ensure the working of the LAG more widely embedded with other activities of the area. The interviewees also view the LAG as a very small body in the overall scheme of England.

A more mixed judgment exists for the implementation of funding programmes. This is due to the bureaucratic difficulties in ensuring financial compliance and the business of good government. Additionally, the difficulty of making an application and the discomfort caused by rejections for both the applications and the decision makers.

Most interviewers expressed several fears relating to the continuity of funding beyond the end of the LEADER 2007-2013 programming period in order to be coupled with a desire for long-term objectives as the LAG has a too short period to bring about real change. There is also a desire for greater devolved authorities and a wish for more involvement of the national and local authorities. Nevertheless, whatever the reality of such concerns, the real challenge for the CWWW LAG is to carry forward the lessons derived from working together to find solutions for local problems into a new era in which European Union funding could become a thing of the past. 


\section{The Implementation of EU Rural Development Policy in Italy}

In Italy rural development policy derives directly from the EU agricultural policy and regional development framework. There are no state-funded programmes explicitly oriented to the development of rural areas.

Particularly important milestones in the evolution of the Italian rural policy have been the Structural Funds programming periods. The first programming period (19891993) introduced the principles of the concentration of resources on specific priorities implemented through a territorial approach based on synergies and partnership at local level, coordination and integration of the interventions.

"In the framework of the programming process, the wider diffusion of participatory methods and particularly of the bottom-up approach encouraged the involvement of the rural communities in the rural development policies at national, regional and local level and in the several phases of the programmes from their definition to their implementation and management" [56] (p. 26).

During the second programming period (1994-1999), the rural administrative structure for the implementation of regional programmes was strengthened. New bodies and policy instruments were created at regional level in line with EU cohesion policies and the importance of the public-private bottom-up approach was reinforced. The reform of the Structural Funds introduced within Agenda 2000 for the 2000-2006 programming period played a key role in raising the objective of more effective involvement of the Italian government in EU policy making in terms of planning modalities and intervention, the principle of subsidiary and operational decentralization [57]. During this programming period, the southern regions allocated more resources to rural infrastructures and to social capital while the governance framework at central and local levels continued to be improved because of the introduction of new monitoring and evaluation methods.

Concerning the 2007-2013 programming period, two documents guided the rural development policy. The first is the National Strategy Plan (NSP) produced by the Ministry of Agriculture; it covers the 21 regional Rural Development Programmes (RDPs) funded by the EAFRD. The second document is the National Strategic Framework (NSF) issued by the Ministry of Economic Development covering the regional operational programmes funded by the Structural Funds ERDF and ESF. The two documents are strictly coordinated and are a first attempt to achieve an institutional dynamic with strong relationships at the central level [39].

The NSP defines the rural development strategy through the three main targets of EU policy: (1) to improve the competitiveness of the agriculture and forestry sector; (2) to valorize the environment and countryside through the management of the environment; (3) to improve the quality of life in rural areas and the diversification of economic activities [58].

The NSF, in turn, defines the regional development strategy, both urban and rural, through two main objectives: (1) to improve the conditions to facilitate the development of agri-business activities and other economic activities; (2) to improve the attractiveness of rural areas through the diversification of the economy and the improvement in quality of life [59].

From an analysis of the programmes, it emerges that the rural development policy framework in Italy "remains predominantly primary sector in focus; it tends to favor capacity to spend over "programming effectiveness" and it lacks a "distinct, strategic integrated rural vision" embracing all aspects of rural policy beyond the EU funded programmes" [58].

The high priority assigned to the agricultural sector is due to the fact that rural development programmes are planned and implemented through regional agricultural departments. The socioeconomic partnership that participates in the defining the programme content is characterized by the presence of the agricultural associations which aim at maintaining the status quo and at resisting diversification of agricultural activities. 
The reality is also confirmed by the fact that Italy allocates low levels of funding to economic and social policies for rural areas for supporting the diversification of the economy and the enhancement of quality of life within the regional development programmes.

Finally, the separation of rural roles at national and regional levels needed to reorganize them at local level through a variety of intermediary agents and institutions such as the LAGs, the provinces, the municipalities. Their joining function is fundamental, and they need to be cross-sectoral by including the public and the private sectors as key facilitators with a capacity for innovation [58].

\subsection{The History of the LEADER Approach}

Quantitatively, after the significant growth in the number registered in Italy from LEADER I to LEADER II (29 to over 200), the number of LAGs decreased to 131 in LEADER + and then further increased to 194 in the 2007-2013 programming period. In terms of quality, however, special attention should be paid to the changes that have occurred in the nature and functions of local partnerships, especially in the most recent period. As regards their nature, local partnerships have gone on the one hand, in the direction of a greater balance between the public and private side and on the other, to a wider representation of different local interests, with a growing involvement of more people coming from outside the agricultural sector and resulting in a diversification of the internal composition. Concerning the functions of the LAGs in the local context, it should be noted that they, as the managers of the funds at local level, have become, in many cases, real development agencies with objectives and strategies that are certainly governing the use of funds allocated by LEADER [60].

In Emilia-Romagna region, local institutions are very active in the constitution of Local Action Groups which resulted in an increase from no LAGs during LEADER I, to four LAGs during LEADER II and to five LAGs both during LEADER + and the 2007-2013 programming period. They promote the constitutions of local partnerships with the private sector in order to create cooperation of territorial programming and governance and to diversify the local economy in tourism activities, valorization of historical and cultural heritage, the preservation of natural resources and landscapes, and the enhancement of the quality of life in rural areas [61]. The LAGs in this region are considered by the National Rural Network of Italy to be those with the most political and functional autonomy as they were given the capacity to choose either the eligible municipalities where to intervene as the socio-economic fields of intervention. Furthermore, the capacity to combine the political and functional autonomy gives LAGs an institutional prestige because they are considered as competent by the regional administration and by local stakeholders [60].

Concerning southern Italy, Puglia region distinguishes itself by being one of the most advanced southern regions in implementing a bottom-up approach that considers the aspect of rurality in terms of territorial concentration, with partnerships at local level, between the different levels of local government and socio-economic actors and at vertical level between government and institutions [62]. The integrated planning represents a change from the top-down approach to rural development policies; the planning responds not only to economic objectives, but it is also a change in the direction of more participation and cooperation among local public and private actors.

The number of LEADER groups increased from two LAGs during LEADER I to 17 LAGs during LEADER II, decreased to nine LAGs during LEADER + and increased to 25 LAGs during the 2007-2013 period.

In this context, the LEADER approach has emerged as one of the programmes which looks at the development of the territory and what best represents the new course of rural policies. More specifically, the LEADER in Puglia is an example of a development within micro-territorial systems although it was initially ignored by a region where actors were used to a large influx of public funds.

"However, thanks to the lack of political pressure on fund allocation, small rural communities were free to promote the creation of LAGs and to use them to achieve a shared 
vision for local development. In this context, many LAGs worked as promoters of new initiatives and coordinators of initiatives already diffused in the territory, managing to amplify their positive effects and consequences" [62] (p. 117).

\subsection{The Case of Delta 2000 LAG in Emilia-Romagna Region}

The territory of the Delta 2000 LAG is located in a wetland between the provinces of Ferrara and Ravenna along the delta of the river Po. The area of approximately 717 square miles with a population of more than 100,000 people, includes 19 municipalities (13 municipalities in the province of Ferrara and six in the province of Ravenna) that are partly or entirely within the Po Delta Regional Park area of the Emilia-Romagna region. This is one of the most interesting environmental areas in Europe, situated in a valley where the river Po runs. It is a natural ecosystem, which is one of the richest and most attractive in the national territory in terms of agricultural production and rural tourism. It hosts the biggest wetlands area in Italy, made of canals, rivers and navigable lagoons, biodiversity, historical and architectural heritage. Besides the Po Delta regional park, the area includes many Sites of Community Importance and Special Protection Areas, as well as regional and national natural reserves. In the past, these environmental assets and local specificities were not adequately valorized since the residents had the perception of living in a marginal area with a limited awareness of the potential of the wetland, of the environmental and cultural assets of the park and of some traditional local products. The economy is more oriented to agriculture, fishery and tourism which offer occasional jobs and with high rates of unemployment for young people and women [63].

Since 1988, with the establishment of the Po Delta Regional Park, a policy of protecting and enhancing one of the richest and most interesting natural environments across the country has been pursued. LEADER has been an opportunity to complement such policies with the qualification and promotion of initiatives, implementing a strategy that is based on more qualitative, sustainable and responsible growth, favoring controlled development that enhances typical aspects related to an environmental context, enhancing local character and peculiarities. For the 2007-2013 LEADER programming period, the LAG is one of five in the Emilia-Romagna region with a total budget of EUR 20.3 million, including public and private sector matched funding. The mission of the LAG is to implement a local development process based on self-determination of local communities aimed at recovering local environmental, social and cultural resources. By identifying local needs and resources, the LAG implements the necessary projects in order to support economic growth and to create new development opportunities [64].

The strategic plan developed by the LAG derives from the quantitative and qualitative assessment of the needs arising from the territorial analysis and during the consultation phase which saw a strong involvement of local actors and led to the organization of several meetings with the aim to collect various project proposals from public subjects and economic operators within the territory [65].

Since the population residing in the rural areas plays a central role, the overall aim of the LDS is to improve the competitiveness of the territory, its distinctive features and its quality by reinforcing its identity through the involvement of the local population.

The interventions focus on the prevailing economic sectors such as agriculture and tourism, the qualification and promotion of wetlands, specialized and high-income farming, and marketing of local products. This is achieved by funding projects which contribute to supporting local development strategies through local partnerships, bottom-up planning, multi-sectoral integration and cooperation between rural areas to raise public awareness of the natural heritage of the area; improving competitiveness of the Delta area with the aim of strengthening the traditional productions linked to the specificities and traditions of the territory and to promote them on a national and European level; valuing the environment and landscape to improve biodiversity in order to make the Delta area more attractive at national and international level; networking of environmental, social and cultural heritage 
to improve the quality of life, diversify economic activities and enhance the multi-functional role of the farmer.

\subsubsection{Origin and Composition of the Partnership}

Delta 2000 was founded in 1994 as a non-profit association to implement the will of some local governments and act as a reference agency for public entities, associations and private economic operators of the Province of Ferrara.

In 1996, the LAG became a limited liability consortium by consolidating its role as a development agency. This involved the LAG taking the management of various financing programmes and managing the Community Initiative LEADER II for the period 1996-2000. During 2000, as the LAG assumed the management of the LEADER + programme, the area was extended to the province of Ravenna. Currently, the LAG partnership consists of 93 members-out of which 27 partners are from the public sector-representing the main institutional components, economic and social territory [63].

The reasons for the LAG initiation and the actions that have been made are bound to the Delta Park. The Delta Park is situated in an extremely urbanized area and is where the emergence of an environmental protection tool to support the population also needed incentives, for its success, to appear immediately as a factor of development rather than conservation. The LAG and its ability to move not only in technical terms but also in terms of animation helped farmers understand that the park is an opportunity and not necessarily an obstacle to their productive activity. It also persuaded another part of the population that the park and therefore the LAG could be a driving force for a new phase of growth, development and integration between the so-called seaside tourism and a new, softer rural tourism which could affect large areas of the territory, in other periods of the year and not just the summer [56].

In this context, the LEADER approach has allowed territories and different economic and institutional entities to use this tool, for the exploitation of locally typical products, the focus on quality farming, and for the recovery of urban and rural villages. The LAG then found in LEADER programming the opportunity to assess the territory, to identify the aspects that could be improved and valued and to create opportunities for businesses. Consequently, from this point of view, the LEADER approach has allowed public and private actions to combine in a vision that is to grow the whole territory and to fully grasp its resources.

\subsubsection{Organization, Operation and Involvement}

The Delta 2000 LAG represents a successful implementation experience within the LEADER approach; it has stimulated participatory processes by the involving of the territorial population together with local bodies, economic operators, social partners and the spontaneous aggregations of young people and women along with the regional institutions [56].

They were involved during the planning and implementation of the LDS and the LAG carried out a considerable animation activity by giving particular attention to the territorial aspects.

The participatory methodology has been realized through the setting up of several bodies that have accompanied the LAG in the definition and articulation of the integrated design and system proposals and in the selection of the projects that can be funded.

The function of these bodies is to involve a variety of stakeholders engaged daily in the planning of the territory, assisting their work with experts and local community actors in order to create real participatory working groups with the aim of integrating and correlating public and private planning [65].

The Shareholders Assembly and the Board of Directors are the decision making bodies of the LAG. The Shareholders Assembly meets at least once a year for the budget approval and when there are important things to discuss about strategies, guidelines, and the issues dictated by legislation. The Board of Directors consisting of members from the 
agriculture, the tourism and the cooperatives sectors meets on average once a month and it is informed on all activities of the LAG, such as on the approval and opening of call for tenders, the mandate to open a public notice contest, and is informed about the state of the implementation of activities.

The main structure is the "Interprovincial Coordination Committee" (ICC) which includes the Po Delta Regional Park, the Provinces and their Chambers of Commerce. This Committee has a strategic role as it is in charge of programming and implementing the LDS.

Participating Working Groups (PWGs) are also set up, coordinated by the LAG and formed by local technical experts appointed by the ICC. They proceed with the definition of the territorial level integrated projects and plans, which are individually identified, based on specific assessment methods.

Another structure is the Steering Committee (SC) which includes institutional representatives and officials operating in the two Provinces and in the Chambers of Commerce, in the Park and in the municipalities. The SC has a more operational functional role concerning the coordination and the integration among the local actors and has also a consultative role for the definition of the funding calls and the promotional material.

The eligibility and qualitative assessment of applications is carried out by two committees: the "Technical and Scientific Committee" (TSC) and the "Technical evaluation Committee" (TEC). The TSC is composed of professionals in the fields of environment, tourism, handicraft and carries out the assessment of the projects which are directly implemented by the LAG. The TEC is composed of external experts that are in charge of the evaluation of the applications submitted by potential beneficiaries.

The LAG is also equipped with a flexible technical structure organized with employees, professional technical associates and thematic experts [63].

\subsubsection{Outcomes, Achievements and Added Value of the Local Partnership Practice}

Since its foundation, the main objective of the LAG has been to value and integrate the resources and economic activities present in the territory in an integrated and organized way, in order to trigger a local development process based on the self-representativeness of the rural communities. By identifying, designing and implementing actions aimed at the growth and support of the local economy, significant opportunities have been created for the development of the area, focusing attention and commitment not only on the resource system and on local potential, but also of the critical system of the area.

Through LEADER, the LAG identified, adopted and developed a participatory approach at all levels that enabled the development of an integrated system design and integrated in terms of territorial, sectoral, and programming dimensions [56].

The LAG working made the valorization and the transformation of territorial resources possible with the aim of contributing to the economic growth of the area in terms of employment and services and to the preservation of the natural and cultural resources.

With the LAG's intervention, Delta Po Park became an eco-tourist destination for birdwatching with relevance at international level thanks to the presence of rare species of birds. This makes it particularly interesting not only for researchers and naturalists but also for those who want to discover and experience nature and its resources. The development of sustainable forms for the enjoyment of these areas represents a great opportunity not only to valorize and promote the area but also to foster the strengthening of the link between economic operators and the population to the territory [65].

With the aim of contributing to the increased awareness of the region's unique avifauna, the LAG carried out some relevant interventions aimed at strengthening the birdwatching activity. It also created a market by attracting experts and presenting the region as a destination for outdoor activities such as guided tours, workshops and didactic activities for schools.

The increase of visitors' presence in the autumn and spring time for birdwatching, represents the success of the idea and gives the opportunity to promote new kinds of 
eco-compatible tourism (fishing, bicycle tourism, river tourism). Young graduates have set societies, cooperatives of environmental education guides and whose laboratories are focused on $80 \%$ of birdwatching on the whole park territory.

The development of sustainable forms for the enjoyment of these areas represents a great opportunity not only to valorize and promote an area but also to foster the strengthening of the link between economic operators and the local population.

These are the main motivations that led the LAG to initiate a series of initiatives to consolidate and structure the Delta's environmental heritage, qualify, organize and create a network of the environmental, cultural and landscape resources, supporting the diversification and qualification of tourism at territorial level and the agri-food production.

In this area there was really only a vision of beach-centered tourism while the value of LEADER was to also grow in the culture of our entrepreneurs the valorization of those parts of the territory, of those peculiarities that were previously not valued. It was also thanks to these initiatives like organizing educational tours in the valley with the local operators, aimed at informing the operators and entrepreneurs that the richness of this territory has a much wider wealth potential than that which can be derived from the beach and the coast because we do not have a splendid sea that arouses emotion.

The main intervention concerned the strengthening and improving of the park accessibility, as well as the creation of an integrated tourist service (overnight stays, restaurants, the selling of local products and tourist products focused on natural resources).

The LAG implemented other initiatives by integrating the funds of LEADER with other European, national and regional funds and policy instruments.

Some examples of this are the interventions funded by the ERDF and EAFRD and implemented by the two provinces. These involved the renewal of villages and ancient buildings such as the old theatre, the old market in Goro, the old elementary school in Mesola which has now become a part of tourist receptivity and a part of the library, small scale infrastructure, the creation of bicycle paths and natural trails and the complementary action carried out by the LAG in organizing animation and training activities for professionals in the field of eco-tourism. The LAG also carried out many projects to encourage the integration between the public and private actors with a relevant impact on the valorization of territory [56].

In pursuing this objective, the LAG implemented a governance system at the local level with the creation of networks of actors and the establishment of relationships at European level between the territory and those with similar wetland conditions where other LAGs work.

The interprovincial character of the LAG promoted territorial integration by valorizing the natural and local resources of both provinces and strengthened the cooperation between local institutions and economic operators by raising the awareness of the territorial potential. It also fostered the competitiveness among the farms of Ferrara which were less competitive, and dynamic compared to the farms in Ravenna.

Beside its role as Local Action Group, Delta 2000 is also a development agency as it offers technical assistance to local institutions, associations and stakeholders in drawing up, implementing, coordinating and managing actions and projects in the framework of economic and territorial programmes. The LAG has become a reference body for the territory where we can find opportunities not only suited to LEADER but also to put projects and to find technical assistance funds. This helps them to make further budgets.

Finally, the organization of the LAG based on a wide partnership had a strong cultural impact, both in terms of the methodology used in the implementation of the projects and human capital thus becoming a new working model through the exchange of information and skills.

To talk with private operators, to create dialogue with institutions, to be able to let institutions communicate with private operators, the LAG becomes a sort of reference point for developing consistent and shared strategies, but consistent with what has actually been developed, of what has been the evolution of the territory. 
Therefore, the experience gained in these years and the results achieved allowed the LAG to refine the methods and tools for applying an innovative approach and methodology to the area that is of utmost importance. Here, the bottom-up approach, to be effective and to ensure a community-based design that integrates and is complementary to existing programming tools, requires constant fieldwork. This means going 'beyond' the negotiations and consultations by involving the institutions, not only at the political but also at the technical level, as well as the economic operators of the territory, the social partners and the spontaneous forms of aggregation of young people, women, etc.

\subsection{The Case of Capo S. Maria di Leuca LAG in Puglia Region}

The area of the Capo Santa Maria di Leuca LAG is located in the south-eastern region of the Puglia Salento peninsula and is surrounded by the sea on three sides. It has a land area of approximately 167.52 square miles and a population of more than 112,500 people. The 18 municipalities that are part of the area are mostly small but only a few miles apart and quite integrated with each other. This territory sums up the whole set of orographic, soil and the human settlement of the peninsula: the various types of coastline, the reliefs of the Salentine ranges, the plains with a varying degree of cultivation and fertility, the range of various size municipalities, all located closely to one another and united by a dense network of minor roads.

Equally homogeneous is the type of production, both agricultural and manufacturing. The agricultural sector is characterized by small sized farms and low levels of production with a dominance of olives and cereals. In the area there are also crafts and small businesses in the clothes and furniture sectors which are dependent on orders, from larger companies from the center and north of Italy.

Today, the area of Capo Santa Maria di Leuca is a strong tourist destination not only because of the sea, but also for important historical, cultural and environmental resources. The great opportunities that agritourism could have for the preservation of the environment were underestimated as well as for the promotion of tourism and for the valorization of ancient rural buildings. The same economic operators and the general population in general encountered a big limitation. On the one hand, young people did not have an entrepreneurial mindset and were not accustomed to creating debt, and, on the other, there was the mistrust of the owners, in general, lawyers, doctors and professionals, who argued that being a territory with many difficulties in its infrastructure profile, tourist activity took place only in the summer [66].

For the programming period 2007-2013, the LAG is one of 25 in the Puglia region with a total of EUR 18.5 million including public and private sector funding. The overall objective of recovering the identity of rural areas is the key to the interpretation of LDS and objectives. The activities to support and implement this objective are therefore those that have the capacity to enhance the values of local identity such as handicrafts and foodstuffs that are representative of the local way of life, rural tourism in its various declinations such as recovery of an architectural heritage and a system of services for knowledge of the territory and its productions [67].

\subsubsection{Origin and Composition of the Partnership}

The LAG was constituted in 1991, in the form of Limited Liability Company. The corporate structure, despite the initial efforts directed at the involvement of the various local actors, consisted of eight members.

The establishment of partnership was mainly due to a group of people who, although not joining the LAG shareholders, have been active in the drafting of the LDS and the promotion of the initiative in the area, becoming animators of the LAG. These subjects around the trade union "CISL-Confederazione Italiana Sindacati Lavoratori" (Italian Confederation of the Workers Unions)' were linked by friendship and their engagement was mainly on this basis. Each one of them had his own skills, so there was someone who had an in-depth knowledge of the area, a sociologist, an accountant, and ultimately the 
main creator who played a key role not only at the time of the establishment of the LAG but also throughout the LDS implementation during the various programming periods [66].

The first programming period they made was during LEADER I. It was still a time where the true measure of the needs of the territory was not the partnership of the LAG but a direct relationship between the LAG and the territories, through the beneficiaries and somewhat with the local administrations and the second element was the ability to make a proper analysis of the needs that led to the identification of the objectives.

Subsequently, the experiences and competences accumulated over the years, trust in public institutions, the local population and the economic system, as well as the successes reported, pushed others to join the LAG. It was a process of trust that was slowly acquired by the LAG and which involves not only the local population but also the same administrations that, if at first they were particularly reluctant to participate in this initiative, they are now asking and inquiring about the possibilities the LAG offers to implement some interventions.

Nor should it be underestimated that the theme of rural development was not immediately understood; the widespread understanding viewed such as a focus as synonymous with backwardness, something linked exclusively to agriculture and hence to be rejected. The widespread mentality considered in negative terms all that was related to agriculture. Listening to rural talk implied, necessarily, something that had to do with farming and was rejected and not considered. It was thought that development was only industrial. There was a widespread culture that had tried to eradicate the agricultural tradition of the area due to the many problems that afflicted the sector to turn almost exclusively to industrial promotion [66]. It was not easy to tell farmers what it meant to shift from agricultural land production to service farms. That is why in those years the function of the LAG was to educate, communicate and train this new profile of the farmer, which was required by the establishment of funds for Community Agricultural Policy, and they had a great role in this going home by home, church by church, shop by shop, farm by farm, municipality by municipality to make it understood that the very strategic approach of agricultural-environmental development was changing, namely the famous sustainable development, which the European Economic Community had sanctioned through the regulations. There were many formal and informal meetings with the potential beneficiaries to give extensive information on what the LEADER approach was and the objectives of the LAG's strategy [66].

All this has enabled local institutions to be more aware of the problems of the area and to understand the need to play an active role in the territorial development through the implementation of joint actions. In addition, local authorities played an important role in the dissemination of the initiatives organized and in the publication of the calls launched by the LAG.

This situation has therefore required extensive work of engagement and mobilization of the territory. Many beneficiaries were directly contacted by the LAG animators who personally visited the potential beneficiaries, explained the LEADER spirit and tried to convince them of the opportunity offered.

The LAG partnership consists of 120 members and it expresses in a balanced way the local partnership, representing the main institutional components, economic and social territory. More specifically, 29 partners are from the public sector and 91 partners are from the private sector (associations of the agriculture, culture, craft, trade and enterprises sectors, cooperatives working in the sector of development and promotion of the rural territory, and private operators interested in the development of the territory) [66].

Each partner participates in different ways within the LDS, also depending on their role, sharing their strategy and pledging to strengthen the image and presence of the LAG in the territory. 


\subsubsection{Organization, Operation and Involvement}

With regard to the LAG management organization, there is no rigid division of roles between staff, but, on the contrary, there is a wide range of people available to collaborate.

The administrative bodies are the Shareholders' Meeting, the Board of Directors and the Management while the technical and organizational structure is composed of a Technical Committee, an Animation Structure, and an Administrative Secretariat [66].

The Shareholders' Meeting has the duties of appointing members of the Board of Directors to approve the annual and multiannual financial statements.

The Board of Directors has the task of managing and implementing activities falling within the scope of the corporate subject.

In addition to the steering bodies, the construction and implementation of a process require a continuous involvement of public and private actors involved in LDS dynamics. To this end, two arenas of participation and leadership are set up in the LDS implementation process: the Technical Partnership Committee (TPC) and the Permanent Forum of Integrated Projects (PFIP) [67].

The TPC expresses its views on the strategic guidelines for the implementation of the LDS, proposes initiatives to be funded within other community, national or regional instruments, publishes calls for proposals, assesses the territorial promotion plan, and carries out delegated functions as directed by the Board of Directors when appropriate.

The PFIP is set up with the mission of gathering around a single table all the people in the area who have implemented the LDS. The forum is responsible for coordinating the projects implemented under the LDS, identifying forms of functional and managerial integration between the various interventions, proposing initiatives and programs for the promotion of routes and paths within the territorial offer promoted by the LAG.

Public bodies are actively involved in the presentation phases to the local population; they also help develop the economic subjects of the LDS and the measures to be taken when publishing the calls for proposals and disseminating the results that will be achieved. In order to foster a widespread dissemination of the opportunities contained in the LDS and to give all potential beneficiaries the opportunity to take part in the initiatives, the LAG favors the use of informative and awareness-raising meetings with potentially interested local actors, the distribution of information materials and posters in the municipal area, and the creation of sections of the institutional websites dedicated to the LEADER approach [67].

Finally, private companies and other participants in the LAG represent the most significant part of the partnership. They are the first witnesses to the local development strategy of the LAG. These private companies are asked to transfer their experience to the new beneficiary companies, including and above all through the specific actions to be put in place by the LAG during the implementation of the strategy [67].

\subsubsection{Outcomes, Achievements and Added Value of the Local Partnership Practice}

The LAG has set up its activity focusing on a micro-projects strategy and the involvement of a large number of public and private entities. All of this was done to increase the sense of belonging by the local population for the area and to create the perception of being the main actors in the development of the territory [68].

As the territory has a long heritage of not appropriately valuing the endogenous resources, ranging from the region's environment and history to its tradition and culture, the LAG has identified and sought to bring these things to light with the tools described above and with the most appropriate modalities. The promotion of rural tourism has been the focal point of the LAG for which it has decided to allocate about $40 \%$ of its available resources. Bringing the consumers into this space and making them part of the production and training processes, tourism is able to become the best and most profitable form for marketing and promoting local products. For rural tourism to take off and have positive implications for the economy of the territory, it was necessary to create the optimal conditions such as better organization of services, greater capacity of the local system to respond to the market and to offer higher quality products [66]. 
In 25 years of activity, the LAG has been promoting and managing vocational training and upgrading courses for young agricultural entrepreneurs and young unemployed people involved in the creation of farm businesses, providing advice and technical assistance services to local authorities and private companies, informing young people about business opportunities and financing their entrepreneurial ideas, and organizing promotional events in Italy and abroad.

The LAG's strategies to ensure active rural development have been targeted not only on the involvement of the population and the training of jobseekers but also to disseminate news of the benefits that LEADER could provide from local rural development.

The activity was based on the coordination of several synergistic actions between the productive sectors, the local population, the associations, the public bodies and the activities of a small but strong territory, capable of inducing an integrated and homogeneous development of its rural areas. The ability to listen, observe local communities and be proactive, the spirit of research, and the constant attention to discovering new opportunities for intervention on the ground, all have been the winning cards that the LAG has been able to play in order to develop substantial entrepreneurial ability within the area.

Today, the LAG represents a reference point for the entrepreneurial system and for the public administrations of southern Salento, realizing a multifunctional center, within which a series of services are provided for the territory, with a permanent exhibition of typical products from the area, the iconographic and multimedia repertoire of the historicalarchitectural and environmental heritage, the tourist information point and receptive offer of the territory.

As the LAG's area is characterized by historical and natural resources of great interest, the LDS has sought to enhance and improve the offering tourist, not only from an environmental and cultural point of view but also in terms of receptivity. An innovative initiative is that of the "Village Hotel" created in the historic center of the municipality of Specchia and then extended, given the positive results achieved, to two other municipalities. The action consists in the restoration of ancient uninhabited houses, to be used as a hotel in the summer months. The management and leasing activity are carried out by the LAG. Thus, the recovery and revitalization of historic centers have been initiated.

With this project, a very innovative intervention model has been developed both in terms of the recovery of the abandoned old town, aimed at tourists and in terms of rural tourism. The ancient hamlet of Specchia was chosen, as it is one of the best examples of a preserved historical center in Puglia and is particularly important for its historical significance with regard to the 16th century peasant society.

Another important intervention has been aimed at the recovery, preservation and enhancement of four forests of the Mediterranean scrub: the woods of Cardigliano and Specchia, the Park of Querce (Oaks) in Castro, the woods of the Vallonee in Tricase, and the Park of the Baronale (Baronial) Palace in Tiggiano. Through these interventions, the spaces were made available, educational boards, billboards and benches were installed, and guided tours were organized [68].

In view of the organizational shortcomings affecting the tourism sector, tourist packages were set up which were promoted through participation in national trade fairs, workshops and meetings with tour operators, associations, and organizations.

Another goal identified was the valorization of craftsmanship through the creation of an exhibition and sale point of the products from the area. This way, the creation of a network of local operators was attempted to enhance the typical handicrafts such as the processing of olive wood and the typical stone-cutting of Lecce. Collaborations have been developed between farmhouses, artisans and traders of typical products. The use of typical ceramics and wood processing have become part of the agritourism furnishings, along with exhibitions of local artisan products. Small-scale production was also encouraged, by solving the old problem of the lack of transformation of local products such as olive oil, wine, preserves and the other by linking manufacturers with transformers. 
All this was possible not only because some people have become a vanguard group in design, but because they have been personally engaged, and operate with a strong initiative spirit.

Finally, the LAG has set itself the objective of becoming a self-supporting development agency, so that it can continue to operate at the end of the LEADER Programme. With the aim of providing real services to local businesses and institutions, the LAG provides technical assistance and consulting services on various financing opportunities for the development of the area [66].

\section{Conclusions}

The research drew on the experience of four EU LEADER LAGs/public-private partnerships operating in the UK (Argyll and the Islands LAG-Scotland and Coast, Wolds, Wetlands and Waterways LAG-England) and in Italy (Delta 2000 LAG-Emilia-Romagna Region and Capo Santa Maria di Leuca LAG-Puglia Region). The aim was to analyze the conditions, including political arrangements and actors, that facilitate or hinder the development of the partnerships and their workings for formulating and implementing rural development strategies for their areas. In addition, the research assessed the added value that flows from the bottom-up approach to local development processes. While the MLG theory served as a basis for the policy studies and has been helpful in mapping the general framework of the structures implementing LEADER in the UK and in Italy, the case studies approach was very helpful for providing information about the distribution of power and enabled to analyze the mechanism adopted to reproduce and transform the European rural development policy implementation and to focus how those decision making structures function in both countries.

Triangulation was the main method for crosschecking data from different sources and provided a better understanding of the complexity and variety of the different existing interpretations in the social and political world. Within this framework, similarities and differences in opinions and interpretations were taken into consideration and further primary and secondary documentation were examined when substantial differences between sources were found.

The following four questions were identified: (1) What conclusions do we draw about the emergence and the composition of local partnerships? (2) What are the key characteristics of the LAGs' working mechanisms employed to address rural development? (3) What considerations do we draw about the outcomes and performance deriving from the LAGs working in rural development? (4) What is the added value of the LAGs that flows from the bottom-up and partnership approach to local development process of the areas they serve compared to the more conventional governance approaches?

These four questions are addressed in this section under two subsections. The first subsection answers, in a transnational perspective by comparing the UK and the Italian case studies, the first three questions and elaborated on the rationale for local partnership processes and the evidence regarding their set-up and working mechanisms. The second subsection answers question four and reflects on how a LEADER LAG and its public-private partnership can be considered as a governance instrument which gives an added value for the development of rural areas compared to a conventional governance approach.

In the final section some policy recommendations and suggestions for future research are provided.

\subsection{Summary of Main Findings}

The analysis of the case studies suggested that the practice of the local partnerships has emerged from a set of factors related to the local countryside context. Such factors include a socio-economic change of the rural areas, a political and administrative restructuring and the concept of a partnership approach as an effective development tool. This approach 
gives back the control to rural areas so that their development activity is closer to local needs and is therefore preferable to a conventional top-down approach.

Currently and throughout the preceding 30 years, rural areas are witnessing economic diversification, where rural areas are no longer exclusively tied to agricultural activities and where development policies and approaches are undergoing considerable revaluation. Rural development is no longer exclusively concerned with the production of goods but has become a locally dependent, multi sectorial and shared challenge in which international, national and local authorities, economic and social actors as well as local people are all influential and play a collaborative role. All four case studies have demonstrated this movement towards the diversification of the economic approach and social activity, despite the initial resistance.

In this conjunction rural authorities have promoted an integrated and participatory approach as a prerequisite for addressing issues and challenges for the development of rural areas at local level. This approach can be considered as a new government form including the institutions and actors drawn from local government and beyond. This new governance approach reflects the promotion of greater interaction between the public and the private sector and the encouragement of more popular and democratic participation within local and regional governance [69]. Concerning the implementing modalities of the EU rural development policy, both in the UK and in Italy, there are National Strategic Plans (NSPs) which guide rural development policy. The UK NSP provides the basis for the Rural Development Programme for England (RDPE) and the Scotland Rural Development Programme (SRDP). The Italian NSP provides the Emilia-Romagna region Rural Development Programme and the Puglia region Rural Development Programme.

In Scotland, although devolution granted significant autonomy in designing its national rural policy, rural affairs are a matter overseen by the Scottish Parliament with little sub-regional delivery infrastructure. Decisions about policy design remain at national level where the Scottish Executive Department works with DEFRA to ensure that Scottish issues are represented. In England, there are no formal intermediary government layers between national and local level representing an important issue for the delivery of rural development policy. Regional Development Agencies (RDAs), as responsible bodies for negotiating with applicants and making decisions and becoming mature institutions with their own identity, experience of regeneration activity and autonomy to manage their resources, played a central role in the delivery of rural policy. This signified a series of important shifts from an agricultural to a rural focus with policy implications in socioeconomic activities, from a concern for resource management and planning to a concern for people and communities in rural areas, from seeing the countryside as a unitary space to an acknowledgement of the diversity of rural areas which reflects differing pressures and circumstances as well as distinct governmental and political structures. With the disappearance of RDAs, the socio-economic elements of the Rural Development Programme of England (RDPE) are now delivered by DEFRA, which has the responsibility for the delivering of greater competitiveness in the agricultural sector and for investments in rural areas. The return to a national programme causes the removal of the former regional flexibilities to deliver approaches attuned to regional circumstances. Within this framework, where regional local strategies are due to disappear, local communities will have a say over developments in their towns or villages while central governments retain control over major infrastructural projects. In the case of Italy, even if the policy priorities are formulated at national level, Emilia-Romagna and Puglia regions implement rural development policies by promoting the coordination with regional policies. Regions implement rural development policies through a bottom-up development model that embraces the aspect of rurality in terms of territorial concentration, integration and concertation with partnership at local level based on the cooperation between the different local government levels (municipalities, provinces, parks).

However, while there are key differences in the British and Italian national and subnational institutional structures which mediate EU agricultural policies, the implementation 
of both rural policies at local level are carried out toward an integrated bottom-up development model.

The consideration of the case studies from two different countries has been very useful in showing that partnership operation raises similar issues and challenges. It was interesting to observe that the attitudes, motivations and also the frustrations and sense of resignation about the practice of local partnership were almost identical.

A further important finding from the comparative case studies concerns the concept and the origin of partnerships.

In the UK there is a great variety of partnerships reflecting an emerging form of governance which has moved away from national and local government administration and has incorporated a diverse range of quasi-government bodies.

Italy does not have a solid tradition of partnership because until the late 1990s the policies for economic development were influenced by theories inspired by a top-down conception of governing. It was only with the diffusion of local development and the bottom-up approach that the practice of partnership became a feature of governance at local level.

The general objective was to introduce a territorial development strategy focusing on the valorization of the endogenous resources through the realization of interventions oriented towards the development of alternative agricultural activities such as supporting the diffusion of local products, promoting tourism in the internal area, and funding projects in the cultural, environmental and economic fields. The strategies of interventions are oriented to professional training and creating employment in the field of rural tourism, promoting opportunities in the innovative production for generating new incomes, increasing participation of local people, valorizing the identity of the area at the cultural and environmental level and in terms of quality of life.

To answer the first question, the process of local partnership building emerged as a key and iterative process with a strong influence of the local context where local conceptions, values, attitudes and mentalities have to be accommodated because they reflect rooted local traditions. Even if in different local contexts the bottom-up initiation is considered a crucial element in the process of local development. It does not simply mean 'from the grassroots', as opposed to the vertical and potentially undemocratic features of the 'top-down' approach; rather, here the accent seems to be placed on the necessity that the collective and horizontal process must come from within the local area, that strategic decisions must be decided and implemented in a decisive relationship with the local dimension.

It emerged that the LEADER partnership formalization involving negotiations of agreements and the adoption of innovative participative methods has not been an easy process. This is particularly true in those areas with different social and institutional contexts and where there is a weak tradition of dialogue, cooperation and associations, have at times hindered progress.

The evidence derived from the case studies indicates that the process of local partnership building relies on the mobilization of a wide range of interests, of a flexible local space, of local resources, ideas and projects as well as of existing structures, organizations and civic traditions. The empirical evidence also emphasizes that essential to local partnership building is the involvement of local actors, the formulation of a clear strategy and the setting-up of effective structures. An important role was played by the local authorities, but the efforts made by key people with energy and local contacts were also crucial.

In the UK, the two LAGs follow on from the previous LEADER + programme. The initiation of both partnerships was characterized by the availability of funding opportunity at European level. The role of the lead partners of the two LAGs (the Argyll and Bute Council in Scotland and the East Riding of Yorkshire Council in England) has been very fundamental in achieving a number of successes within the implementation of the LDS. They encouraged a wider ownership of the partnership and as local authorities they have a relative independence from political and administrative control which helped them to operate in a more innovative and flexible way and thereby they gained local credibility. 
In Italy, the area of Delta 2000 and more generally in the Emilia-Romagna region, there is a longstanding traditional presence of cooperative actions as well as an efficient public administration in promoting and supporting the partnership. The initiative for the creation of the partnership came from the local public institutions that have always played a pre-eminent role and influenced all its developments.

In Puglia, the experience of association and cooperation was particularly scarce. In the case of the area of the Capo Santa Maria di Leuca, the public authorities were not crucial for the creation of the partnership which was instead mainly due to a group of people who were active in the promotion of the initiative in the area.

Therefore, it can be highlighted that a crucial role was played by key people followed by local institutions and private sector organizations who had the capacity to put together different subjects focusing on the specific advantages on the basis of personal contacts and the pre-existence of networks, and previous experience of activities for common development objectives among the promoting actors and that the LEADER funding opportunity was determinant. This speaks to a different dimension of multi-level governance, namely the more horizontal building of relationship and the inclusion of a range of different voices to build a common vision.

Concerning the partnership composition, it emerges that the public sector is strongly represented in all the four partnerships due to its political and financial means and in accordance with art 62.1(b) of the EC Regulation 1698/2005 ( . . At the decision-making level the economic and social partners, as well as other representatives of the civil society, such as farmers, rural women, young people and their associations, must make up at least $50 \%$ of the local partnership ... ). In many cases, local authorities provided the necessary drive and leadership and a measure of political legitimacy that would otherwise be lacking. The categories of actors most represented are public institutions which also include the Chambers of Commerce, the park authorities and the private actors such as the trade associations and interest groups (e.g., farmers and landowners), NGOs with community and environmental interests. The people representing the private sector are not acting as individuals but rather representatives of their organizations and are not also politically elected members of other organizations on rural development. They are organized into groups or organizations and their involvement is seen as active local players willing to commit their time.

To answer the second question, the research findings showed that local partnership operation requires time to mobilize partners, to conciliate and coordinate the differences, to develop communication and agreement to establish a new mode of functioning and a new culture between actors.

Among the interviewees, there seems to be a consensus that the whole point of partnership operation is to bring together a variety of powers, expertise and roles. Instead of talking about the "sharing of responsibility and power" we should talk about an "association of responsibility and power" where local actors take responsibility and play an active part in rural development and this action does not imply that all partners are playing the same role. These fundamental characteristics have made possible several crucial activities for the endogenous development such as the coordination of diverse actors, the integration of interests at top-down and bottom-up levels, and the pooling of resources.

The motivations of the various actors to join the partnership move from taking advantage of the programme funding to resolving the problems in the area. In addition, certain actors have decided to become part of the partnership by virtue of a specific interest. This is the case of Capo Santa Maria di Leuca LAG where the private subjects are clearly getting more opportunities as beneficiaries than the public authorities. The participation of the trade associations is instead due to the fact they see in these experiences new opportunities to benefit that they represent. Therefore, there should not be any surprise if local actors mobilize themselves with the aim to take advantage of such policies as this is coherent with the desire of promoting local integrated development. 
Intrinsic to local activism is the sense of civic responsibility, the sense of being committed to and getting involved in the local area. For some interviewees, this commitment rested on their personal inclination to bring time, experience and support to the area in which they are called to work. For others it is a means of showing a willingness to become part of a community in which they have chosen to live and to take action.

Whilst there is a recognition that rural development requires a collective action, local partnership operation is the result of a long, slow and laborious process. Rural development emerges as a long-term, progressive, comprehensive and pragmatic process that is organized over time. Its existence and longevity depend on the local context, a set of opportunities, on the issues to be addressed, on a broad mobilization of local actors and in particular it is a process which depends on people, their views and reasoning, expectations and vision for the development of their area.

Since the four LAGs are formally constituted organizations as required by their respective national laws for the LEADER programmes, their organizational structure is similar. Partnerships benefit from an effective two tiers structure involving fairly infrequent meetings of an assembly of all the partners and more frequent meetings of a board where real power normally resides and which is supported by small committees composed of professionals in the fields of environment, tourism and crafts. They also express their views for the LDSs implementation, propose initiatives to be funded, publish calls for proposals and assess the territorial promotion plan.

They are all supported by administrative and technical staff with the aim to assure a smooth management and implementation of the activities. Abilities like planning projects and providing technical support to beneficiaries as well as listening to local people and connecting projects and institutions are of vital importance for the successful working of the LAG. In many cases, the staff felt a personal responsibility to the project by providing special support during the planning and implementation phase.

In terms of legitimation of the partnerships, the case studies showed that it derives mostly from the direct involvement of public authorities and less so from involving local people. Further legitimacy is given by the transparent decision making process and also by the funding supervision and monitoring assured by the LAGs as a mandatory requirement from the European Commission. The involvement of the local community activity is generally achieved through the organization of public meetings that imply a large participation even if it happens through the direct participation of the project beneficiaries. The partnerships reveal a strong traditional community identity in terms of activities and resistance to change. They have been aware of the need to involve local communities to bring local knowledge and to strengthen their local credibility. The role of the local authorities was responsive and proactive as they wanted to draft a strategy based on a real recognition of local problems in order to be a convincing bid for getting LEADER resources. In these circumstances, the level of the community involvement was enhanced within the whole rural development process as there has been much enthusiasm, energy and skills. Local authorities played a key role in this process by displaying their capacities which shifted in the recent years from only a provision of services to a more strategic role. This role put the partnerships in a good position in terms of credibility and public accountability and allowed to bring together a wide range of public, private and community and voluntary organizations.

One problem identified in the research findings is the impact of an excessive bureaucracy of the funding programme in terms of requirements for information and inflexible bidding procedures and this brought considerable frustration for staff and applicants. The constraints of deadlines and the need to operate quickly to bring forward projects, strategies and to secure funding are often onerous and cumbersome. For the UK LAGs bureaucracy is perceived by the project applicants as a lot of compliance monitoring and paperwork to do and the LAG administrative structures are expending a lot of effort on this in their spare time as they do have not a fulltime job as LAG administrators. In Italy, an overall excess of bureaucracy slows down the activity of the LAGs which means essentially a lack 
of coordination in the circuit between the local, the regional and the national levels. This inadequacy has resulted in the creation of a bureaucratic model that manifests itself in the rigidity of the institutional instruments. This results in the long procedures for the disbursement of the funds and for the carrying out of the controls which, besides slowing down the activity of the LAGs, obscures the image in the eyes of the beneficiaries.

Other negative factors are the short time perspective of the programming periods and the limited financial resources available for the projects. Thus, even if they are projectoriented in the sense they see their main function as the delivery of their LDS, they have the objective of becoming a real development agency, so that they can continue to operate at the end of the LEADER programming period with the aim of providing real technical assistance and consulting services to local businesses and institutions on various financing opportunities for the development of the area.

To answer the third question, studying the outcomes of the local partnership practice is considered in the literature as an important way of understanding partnership working [70]. When the decision was made to explore the outcomes, the intention was to throw some light on their practice and role in rural development rather than carry out an impact study or any other form of evaluation. The evidence from the case studies shows a number of positive outcomes. First, the successful implementation of rural development projects. Second, the partnerships clearly enhance cooperation between the various sectoral actors and engage and mobilize the community. Finally, there is the creation and maintenance of employment, the creation and modernization of SMEs in an innovative way, the development of rural tourism and the promotion of local products.

In the UK, for instance, in the case of the LAG Argyll and the Islands, the interviewees claimed that the most important outcomes were job creation, the funding of new social enterprises, and infrastructure projects such as the investment in village halls and community buildings improvements. These buildings are very much multipurpose-use and they are designed to be not just an area for people to gather but also for other activities such as sport, meeting rooms, lecture rooms, day and evening classes, adult learning, clubs for the younger people and lunch or afternoon tea clubs for the older people.

The large geographical area has enabled the CWWW LAG to develop a wide and diverse range of interventions within the culture and heritage area. It has created a new understanding of the value of wildlife tourism in the local economy and has encouraged the formation of new partnerships such as the Yorkshire Wildlife Trust and the Yorkshire Water to promote and coordinate development together. The LDS has also given support and advice to businesses, created new employment and encouraged capital investments in wildlife reserves and accommodation.

This is also demonstrated in the case of the Delta Po Park which became an eco-tourist destination for birdwatching with relevance at international level and in the case of the Village Hotel in the historic center of the municipality of Specchia within the area of the LAG Capo Santa Maria di Leuca. The latter innovation was then extended, given the positive results achieved, to two other municipalities. With the Delta 2000 LAG's intervention, the links between economic operators and the population to the territory were strengthened. The village hotel project of the LAG Capo Santa Maria di Leuca represented an innovative intervention model both in terms of the recovery of the abandoned old town, aimed at tourists and in terms of rural tourism.

These development initiatives are followed by other specific business-oriented issues such as the promotion of local products, diversification of the agricultural activities, rural tourism and the preservation of natural and cultural heritage. Competences and knowledge are shared and pooled as a basic resource supporting the action for development as a whole.

In this context, the partnership contributes to the resolution of a number of problems and issues that were seen to represent real obstacles to development in each area such as individualism, the inadequacy of top-down views, and the lack of an integrated vision of development. By allowing the development of a broad vision of problems and issues, the partnership facilitates the definition of commonly agreed actions which are adapted to local 
needs and increases local capacity and interaction between actors and the development of alliances at sector and territorial level.

Moreover, the operation of the LAGs has brought an awareness of valuable local resources, increased awareness of sources of funding and generated the recognition of key people who are prepared to take an initiative if local decision making processes are adequate for the task.

Concerning social exclusion issues, the analysis has confirmed that although it is a common problem in all the case studies, little attention has been paid toward reaching the most vulnerable sectors of local society (women, young people, the elderly, and the disabled) both from their presence in the partnerships and the funding of projects in this field. Encouraging their involvement in the appropriate forums would help to define the objectives of the partnership more comprehensively and would be more in line with the idea of integrated and participatory development.

The observed outcomes emphasize and confirm the need for a partnership operation at local level which has to be as open and flexible as possible and ready to take an active and useful part in the preparation and implementation of development actions.

In terms of delivering rural development, the case studies have shown that the partnership operation helps in the preparation and determination of the local development strategy; enhances the capacity to obtain funding; develops an opening of the rural development responsibility to a greater range of actors and encourages local actors to become involved.

Furthermore, through the involvement of a wide range of local interests, they inject a certain dynamism to get ideas off the ground and make them happen and can be considered as a platform for the sharing of know-how and skills among the partners and endow local actors with a stronger capacity building at local level.

To conclude, the interview findings indicate that the local partnership approach has provided those initial expected benefits of wider participation, greater reciprocity between rural development actors, and an increase in local capacity for development actions. In addition, the present research has also revealed that the local partnership practice is a useful means of providing a diagnosis of local activism and a stimulus to the participation of new and supporting actors.

\subsection{Empirical and Theoretical Contribution and Implications of the Findings}

The success of LEADER LAGs in the implementation of their LDSs largely depends on their ability to produce an added value that extends far beyond what may be expected from the arithmetic sum of their outcomes in terms of results achieved and funds that have been spent. The vast literature on this subject clearly illustrates how there has been a genuine added value in the process of local endogenous development as partnerships are recognized as an effective instrument for introducing new positive orientations and self-confidence among local actors.

Even the most recent Guidelines on LEADER issued by the European Commission provides a consistent definition of this: "The assessment of the added value of LEADER/CLLD refers to the benefits that are obtained as a result of the proper application of the LEADER method, compared to those benefits, which would have been obtained without applying this method" [71] (p. 16). The quality with which this approach is applied therefore determines the intensity of added value that can be produced. Moreover, the European Court of Auditors in its special report claims that

"The potential added value of the Leader approach is not solely in the results and impacts of the physical outputs (the projects implemented with the Leader grants). The community involvement achieved through the bottom-up approach can also lead to less tangible impacts, such as 'capacity-building' and 'empowering the local population" [72] (p. 50).

Several methodological guidelines explain the evaluation of the added value of LEADER approach breaking the method in many parts, corresponding to each of the seven key principles of the LEADER approach:

1. Area-based local development strategies; 
2. Bottom-up approach;

3. Public-private partnership-LAG;

4. Innovative character of actions;

5. Linkage between actions (integrated and multi-sectoral approach);

6. Decentralized management and financial support

7. Networking and cooperation at local, regional, national and European level.

Analyzing the application of the LEADER approach from the perspective of all the seven key principles will provide the full picture of how it has been applied [71].

Through the area-based approach which fosters an integrated rural development through an efficient use of local resources, the programme becomes more accessible and flexible at local level, by enhancing its identity. Here, local people and firms have the opportunity to improve their welfare as well as the valorization of the local natural and cultural resources. LAGs have to transform their needs into local targets when elaborating and implementing their LDSs. The application of the area-based principle in the LEADER approach relies on a local partnership which includes individuals and organizations with a great knowledge of the area. This is further supported by the working of the LAG animators and initiators within the communities which is essentially vital. The presence of sufficient numbers of these individuals makes the bottom-up LAG dynamic work. This arrangement gives significant advantage to the partnership over the local authorities working alone in the same territory [73].

The bottom-up principle reaches more people and fosters activities and resources for animation and capacity building for the development activities at local level. The main benefits of LAGs working consist of taking and widening the range of project implementation and beneficiaries and ensuring funding for project ideas. LAGs are reported to have mobilized small actors and projects and strengthened the civil society in the area from a broader range of economic and social interest groups to increase enthusiasm and commitment, capacity building and social capital creation. Participation may take at the elaboration and during the LDS implementation as well at its conclusions and can be assured directly or through representatives of collective interests. Adopting the bottom-up approach implies empowerment at the local level and can bring flexibility and a higher consensus at local level.

Concerning the added value of public-private partnerships-LAG working, it has to be assessed in terms of how they can help to identify local needs and to harmonize different interests. In the most dynamic rural context in which different development processes have already been initiated, the rural partnerships tend to reinforce the institutional context as they contribute to the development of local democracy. The LAG performance both in terms of efficacy and democratically will determine their ability to provide results in the MLG system. The analysis of the case studies in two different countries confirms that rural partnerships contribute to local development in different forms such as new processes diffused at local level for the reconstruction of the social fabric, the adoption of an integrated approach and the development of local democracy. They are committed to the concept of integrated rural development and the pursuit of living and working in the countryside. The need to preserve and enhance the natural and cultural heritage and local territorial identity and the creation and maintenance of employment are also considered key objectives. In this context, the LAGs are generally effective in promoting and supporting the locally based endogenous development at economic and social level by funding new social enterprises, infrastructure projects such as community buildings for multipurpose use designed for the local people, project for the valorization of the environment and cultural heritage with the aim to create a new understanding of the value of tourism in the local economy and of the local history to give a sense of place to the community people.

Nonetheless, the real challenge for the four LAGs is to carry forward the lessons derived from working together to find solutions for local problems into a new era in which European Union funding could become a thing of the past. The key factors that helped 
the partnerships to deliver the development of their territories are strictly linked to the local knowledge from the partners, the committed staff with flexible skills, and effective management of the funding mechanism. This process also provided partners a strong sense of achievement of the LDS results and doing something worthwhile. Therefore, the working of the LAGs has brought an awareness of the valuable local resources and the recognition that the key people are prepared to take an initiative at local level. These are the actors who do something where there is a general agreement about it through the decision making processes. These effects can be measured in terms of the new ideas, methods and technologies as well as the discovery of the value of local resources that have been reached by the partners, the beneficiaries such as local farmers, local administrations, the population of the whole area and its visitors.

The respondents are aware of the fact that the partnership must operate free from obstacles and with a capacity of adapting its action to the reality of the local context, and by no means should it ever become a bureaucratic organization.

They represent a new base for involving the local people and for the establishment of a new form of cooperation between the public and the private actors. The shift to a rural development strategy at territorial level brought to a new development model based on the assumption that people working at the local level know better how to face the problems within their areas and the endogenous potential they have [74]. In this process, the key people once again play a fundamental role as they are essential not only in the stage of the birth of the partnership, but also in the subsequent operational phases. Such key people have a great capacity for inventing suitable solutions and, above all, the ability to create connections with different actors throughout the territory, with the ultimate aim of establishing new stable networks. This is a further sign of an absolutely non-bureaucratic process, where individuals with direct contacts with the territory where they operate should somehow count more than the structures they belong to. The procedure concerns also the consolidation of the relationships between the regional administration and that one of the local bodies and it also improves the ability of various actors to fit policies to local specificities and to allocate financial resources on specific projects.

In the contexts of the case studies which are characterized by a poor performance of the economic sectors and an isolation from the external processes, the role of the rural partnership appeared to be as an effective instrument for introducing the innovative character of the actions as new positive orientation and new forms of integration among the local actors and for supporting the valorization of local resources. The evidence is given by the implementation of innovative projects in traditional sectors, the mobilization of external funds and the professional competence for rural development. LEADER can create new spaces for rural development to enable social groups to take part in local development initiatives at economic and social level and open up opportunities for different voices to be heard. Innovative activities can be packaged in local development strategies (e.g., rural tourism, manufacture, ICT). Some effects of the rural partnership operation are visible at the local level in terms of direct social and economic benefits. The sectors concern the valorization and protection of the natural environment and the cultural heritage which are often not recognized as a common resource as well as different forms of economic and social support initiatives for the rural population with the aim to increase local incomes and create or maintain job opportunities by introducing new forms of economic activities to decrease the outmigration of young people and to improve the services available to the rural population for rural areas.

Concerning the linkage between actions (integrated and multi-sectoral approach), the added value can be assessed in better coordination within and between administrations as well as important sources and results. The main objective is to coordinate the different approaches, which are predominant in rural development policies to ensure they are not implemented in opposition to one another.

In terms of decentralized management and financing, the national and regional programme makers allow the adaptation of activities to the needs of the area. In some countries, 
the LEADER approach played a particular role in this respect under strong influence of the opportunities provided by the EU Structural Funds. Delegating part of the decision making and management of the funds to the LAGs gives them the autonomy for allocating financial resources to activities in accordance with local needs and the opportunity to adapt their LDSs to changing needs.

Concerning networking and cooperation, the local partnership working develops coalitions at local levels, a broader vision of local needs and issues, a collective commitment for the development of the rural area, a greater credibility from both within the local area and from the outside, a great sense of trust between actors and an integrated strategy to be implemented. Trust means also a friendly atmosphere between local actors and administrators which enables to maintain interaction networks at informal level in the addition to the formal and administrative relationships. Here, the partnerships get the resources required to operate within their LEADER approach to implement their local development strategies and the local actors have the competence and the experience of working through a fluid policy of interactions.

Therefore, it can be said that LEADER is a territorial approach

"by and for the local population and a means to design and implement strategies and actions in rural areas from a bottom-up perspective. It also stimulates the decision-making processes in local socio-economic development which were previously controlled almost exclusively by public actors" [75] (p. 30).

In this context, LAGs, through their partnerships, may play a strategic role for the success of the development strategies since through their competences they are more able to identify solutions to the various problems of the rural areas. In theory, they are open to citizens allowing them to participate in contributing to the diagnosis of problems and needs and in the design of the relevant development strategy. Another important dynamic is the building of trust across a diverse set of local institutions and peoples who were not used to working with each other.

The LEADER approach also gives the local actors the opportunity to elaborate joint strategies for their territories and for their economic activities. It improves their capacity to negotiate common interests and it brings recognition to local partnership that are able to manage development strategies at local level. This highlights the added value of the LAGs that flow from the bottom-up and partnership approach to the local development process of the areas they serve compared to the conventional way in terms of enhanced local participation and ownership of the development activities.

Leading to the final point: local knowledge, know-how and identity, the economic potential of the area, and the commitment of the local population are considered the relevant elements of the partnership. Partnerships and therefore the LAGs are perceived in their areas as the main strategic tools to operate in the local context and to perform a role at least as important as that of the public fund. These financial resources must be the basic point of departure for a bottom-up development activity.

No successful action can be projected or implemented moving from a superficial understanding of the local characteristics, problems and needs. As a matter of fact, one of the greatest efforts carried out by the partnerships was that of putting together as much information and experiences as possible, often carrying out ad hoc studies on which the elaboration of the local action plans was based.

The LAGs have the

"capacity to transform individual interests into more unitary projects usually based on economic development of land-based goods (food, wine, environment, landscape, local heritage, etc.). A single company or economic sector is unable to produce locally-based products ... they are also unable to aggregate firms in the task of controlling free riders" [61] (p. 154).

Hence the capacity to combine the political and the technical autonomy gives the LAGs an institutional prestige which is recognized by both the regional administration 
and the local level. Therefore, the case studies confirm that the bottom-up idea introduced by the LEADER approach has offered new and even unexpected opportunities for the development of areas which are mainly characterized by an economic and social disadvantage [75].

In conclusion, this research analyzed the impact that the LAG level has in terms of local development improvements in the form of leverage, democratization and decision making with a bottom-up approach. It was shown that it would not be possible to implement local projects co-financed by the European Union and to achieve these results if the system were managed only at the national level. Rather, the LAGs and the national level such as the ministries have to be considered interdependent where the types of added value that the LEADER approach provides at the LAG level could not have been provided by the ministries [76].

This is also confirmed by Hooghe and Marks [23] who state that the advantage of MLG is scale flexibility where every governance level engages in the activities that are optimally suited to its skills. The reduced distance costs between project holders and the central level which derives from the inclusion of the LAGs can be considered as the shorter workflow that the MLG system provides to the beneficiaries of the projects.

Therefore, the MLG theory can be considered appropriate as it incorporates the supranational, national and sub-national levels and LEADER presents a governance arrangement which also includes the European, national and local level.

LAGs can be considered as new functional units that have been set up to deal with specific policy tasks and offer new opportunities to participate in EU development policies in order to receive additional resources. In these units it is not just the public administrations that are involved but also economic and social partners and local residents.

"To neglect the inclusion of the local level, as some of the 'grand theories' of European integration do, leads to the exclusion of the most important level of governance within the EU. The local level is vital for the EU for several reasons. And not just because local public administrations implement EU legislation and policies. Being the lowest functional level of the EU, it is the closest to the people and has the potential to make the EU visible to the people. It is at local level that local residents have, to some extent, access to and participate in policy-making" [24] (p. 9).

In this context, local partnerships tend to supplement and not duplicate the work of the local authorities with whom they should be encouraged to have a good working relationship. Their working is important in the implementation of EU policies as the bottom-up approach has allowed local level authorities some policy space to innovate and develop new partnerships across sectors and institutional boundaries.

The case studies' experiences with LEADER implementation have shown that given the diversity of rural areas, LDSs are more effective and efficient if decided and implemented at the local level. Therefore, added value is seen in the LEADER implementation as it leads to improved governance.

LEADER can create a series of tensions both in a horizontal sense, between territories and political and local administrative structures and in a vertical sense, between local and extra-local forces, be they regional, national or European [77]. In the context of the rural development processes, MLG can influence the style of interaction between different levels of institutions, the degree of autonomy of the local partnership and the administrative procedures to be applied.

In theory, under MLG, the role of the state shifts from one of control to one of coordination, using new mechanism to guide a plurality of network actors. The local system is more likely connected on bottom-up processes. Its elements comprise local economic, political and social actors and social networks. They are embedded and oriented towards keeping the processes and benefits of development under local control [78].

According to Yang et al. [79], central government remains influential as it dominates in the policy process design and the procedural enforcements and checks. This influence is perceived as largely negative with increasing bureaucracy which can also influence the 
behavior of LAGs and beneficiaries, including their motivation to participate from fear of potential financial repercussions. Moreover, local actors feel that despite the fact that the regulative role of the national level may come to guarantee accountability and transparency, at the same time they run against the wider EU level intention of bottom-up approach and the spirit of LEADER. Therefore, what initially was intended as something to guarantee democracy and participatory decision making could become a hindrance to the normal everyday operation of LAGs.

Future programmes must take into consideration that the empowerment of the partnership and the capacity-building need a long-term process and that sustainable benefits are gradually achieved after many years. Due to this limit, very few partnerships emerge from the grassroots. Most of them are initiated often by the public sector in response to competitive funding programmes. Here, the public sector acts as a lead funder and organizer by setting the rules of the game and determining the type of partners, the working and the evaluation procedures and providing the office space and administrative support.

\subsection{Some Policy Recommendations and Suggestions for Future Research}

The policy recommendations that emerge from the previous analysis deal with the ways to promote the coordination of policies and funds at the local level. "These levels of coordination seem to be much more important than the EU or the national levels and seem to work even in presence of strong difficulties at EU or national level" [80], (p. 13). Therefore, for the future, an important issue for reflection should deal with the capacity to foster learning processes at the local level with the aim to coordinate the design of integrated development strategies with public policies through support provided by highly specialized expertise and which goes beyond the menu of EU eligible interventions.

In terms of outcomes, they should be also evaluated according to new forms of relationships among the institutional and socio-economic actors and the combination of policy instruments. Therefore, the evaluation of the LEADER approach interventions in terms of time spent to implement the LDS, the capacity of spending funds and the number of funded projects is not sufficient. In this case the evaluation analysis should be carried out relating to the LEADER approach specificities, and the results and impacts deriving from the implementation of the funded interventions. More specifically, the processes such as the participation and the structural changes of the socio-economic improvement of the intervention area, can be evaluated by using different tools such as measuring the relationships and flow between the actors, face-to-face interviews, focus groups and case studies that will allow a contextualization of the implementation of the development strategy.

Concerning the recommendations for future research, since local partnership operation in rural development is mainly dominated by the public sector, future research could be directed to the role of the private sector within local partnership and more specifically how it could be more involved and take greater responsibility in the rural development process. With the exception of the LAG Capo Santa Maria di Leuca, only rarely does the private sector play a major role in the operation of the partnership as distinct from its role as project applicant and beneficiary.

Since the analysis has confirmed that the issues of social exclusion are the themes directly addressed in the LDSs as territorial problems (ageing population, youth unemployment) and it emerged that little attention has been paid toward reaching the most vulnerable sectors of local society (women, young people, the elderly, and the disabled), future research could be directed on how local partnership might more fully involve socially excluded people both in the elaboration and implementation of the local development strategy and as project beneficiaries.

Research on the experience of other spontaneous bottom-up partnerships would be useful with the aim to understand if they are as capable as the LAG partnerships that have been established in response to the LEADER initiative.

The rural focus of the research also poses questions on how the research findings may differ if it were conducted in urban or fisheries areas where the LEADER approach has 
been extended under the broader term Community-Led Local Development (CLLD) in the EU 2014-2020 programming period.

Finally, following the decision of the UK to leave the EU (BREXIT) through the referendum held in June 2016, the Common Agricultural Policy will no longer apply and EU rural development funding and also the LEADER approach will disappear. In this context, a key question for future research is how the needs of UK rural communities could be supported in order to give them the opportunity to preserve and build on the benefits of the LEADER initiatives. The LEADER approach may indeed not be replaced by national measures and there could be also less support overall the rural economy.

"Some rural communities already have the skills, assets, networks and institutional capacity to compete strongly. At the same time, without the necessary resources of support, rural communities that have not yet developed these capacities and networks may become impoverished, losing services and infrastructure, and so become less able to reach their full potential" [81], (p. 3).

Funding: This research received no external funding.

Institutional Review Board Statement: Not applicable.

Informed Consent Statement: Not applicable.

Data Availability Statement: Not applicable.

Acknowledgments: I would like to really thank my academic supervisors Anthony Zito and Phil Daniels, to whom I am very grateful for their invaluable great guidance, patience and always enthusiastic support during my research working. Tremendous gratitude goes to all the interviewees in both the UK and the Italian case studies for their time, availability and useful insights. A special mention goes to David Wilford of DEFRA, Alistair Prior of the Rural Communities Team-Scottish Government, Lorna Elliot and the whole working team of the Argyll and the Islands LAG, Dee Mitchell and the whole working team of the CWWW-Coast, Wolds, Wetlands and Waterways LAG, Angela Nazzaruolo and the whole working team of the Delta 2000 LAG and Giosuè Olla Atzeni and the whole working team of the Capo S. Maria di Leuca LAG.Many thanks to Janet Dwyer and John Powell of the Countryside and Community research Institute (CCRI) of the Gloucestershire University for their friendship and reference suggestions.

Conflicts of Interest: The author declares no conflict of interest.

\section{References}

1. Cavazzani, A.; Moseley, M. The Practice of Rural Development Partnerships in Europe, 24 Case Studies in Six European Countries; PRIDE Research Report; Rubbettino Editore Srl: Cosenza, Italy, 2001.

2. Evans, N.; Morris, C.; Winter, M. Conceptualizing agriculture: A critique of post-productivism as the new orthodoxy. Prog. Hum. Geogr. 2002, 26, 313-332. [CrossRef]

3. Berriet-Solliec, M.; Laidin, C.; Lépicier, D.; Pham, H.V.; Pollermann, K.; Raue, P.; Schnaut, G. The LEADER process as a European policy for local development: A comparison of the implementation in three European member states. In Proceedings of the 55th European Regional Science Association (ERSA) Congress, Lisbon, Portugal, 25-28 August 2015.

4. Shortall, S.; Shucksmith, M. Integrated rural development issues arising from the Scottish experience. Eur. Plan. Stud. 1998, 6, 73-88. [CrossRef]

5. Ward, N. Partnership in rural regeneration. Local Econ. 2002, 17, 256-259. [CrossRef]

6. McAreavey, R. Getting close to the action the micro-politics of rural development. Sociol. Rural. 2006, 46, 85-103. [CrossRef]

7. Lowden, V.; Sullivan, H. Like a horse and a carriage or a fish on a bicycle: How well do local partnerships and public participation go together? Local Gov. Stud. 2004, 30, 51-73. [CrossRef]

8. Derkzen, P.; Bock, B. Partnership and role perception, three case studies on the meaning of being a representative in rural partnerships. Environ. Plan. C Gov. Policy 2009, 27, 75-89. [CrossRef]

9. Esparcia, J.; Moseley, M.; Noguera, J. Exploring Rural Development Partnerships in Europe. An Analysis of 330 Partnerships Across Eight EU Countries; UDERVAL: Valencia, Spain, 2000.

10. Westholm, E.; Moseley, M.; Stenlås, N. Local Partnerships and Rural Development in Europe: A Literature Review of Practice and Theory; Cheltenham and Gloucester College of Higher Education, Countryside and Community Research Unit: Cheltenham, UK, 1999.

11. Larner, W. Book reviews. J. Rural Stud. 2004, 20, 376-377.

12. Bristow, G. Book reviews. Eur. Urban Reg. Stud. 2001, 8, 87-96. 
13. Derkzen, P. Rural partnerships in Europe-A differentiated view from a country perspective: The Netherlands and Wales. Eur. Urban Reg. Stud. 2010, 17, 17-30. [CrossRef]

14. Kull, M. European Integration and Rural Development. Actors, Institutions and Power; Ashgate Publishing Limited: Farnham, UK, 2014.

15. Kull, M. Empowering the Local? Multi-Level Governance and the EU's Community Initiative LEADER + in Finland and Germany. In Proceedings of the Conference New Approaches to European Studies: Social Capital, European Elites, Constructivism, Copenhagen, Denmark, 27-28 April 2007.

16. Bache, I.; Flinders, M. Multi-Level Governance; Oxford University Press: Oxford, UK, 1999.

17. Marks, G. Structural policy and multi-level governance in the European Community. In The State of the European Community: Maastricht Debates and Beyond; Cafruny, A.W., Rosenthal, G.G., Eds.; Longman: Harlow, UK, 1993; pp. 391-410.

18. Charbit, C. Governance of Public Policies in Decentralised Contexts: The Multi-Level Approach', OECD Regional Development Working Papers 2011/04; OECD Publishing: Paris, France, 2011. [CrossRef]

19. Marks, G.; Nielsen, F.; Ray, L.; Salk, J. Competencies, cracks and conflicts: Regional mobilization in the European Union. In Governance in the European Union; Marks, G., Scharp, F., Schmitter, P., Streeck, W., Eds.; SAGE Publications: London, UK, 1996; pp. $40-63$.

20. Wallace, H.; Wallace, W.; Pollack, M.A. Policy-Making in the European Union, 5th ed.; Oxford University Press: Oxford, UK, 2005.

21. Muhammad, S.A.; Noraini, A.T. Decentralization and participatory rural development: A literature Review. Contemp. Econ. 2011, 5, 58-67. [CrossRef]

22. OECD. Building Competitive Regions: Strategies and Governance; OECD Publishing: Paris, France, 2005.

23. Marks, G.; Hooghe, L. Contrasting visions of multi-level governance. In Multi-Level Governance; Bache, I., Flinders, M., Eds.; Oxford University Press: Oxford, UK, 2004; pp. 15-30.

24. Hooghe, L.; Marks, G. Unravelling the central state, but how? Types of multi-level governance. Am. Political Sci. Rev. 2003, 97, 233-243. [CrossRef]

25. Kull, M. EU multi-level governance in the making-The community initiative LEADER + in Finland and Germany. In Proceedings of the EUSA Eleventh Biennial International Conference, Los Angeles, CA, USA, 23-25 April 2009.

26. Norton, A. Western European local government in comparative perspective. In Local Government in Europe: Trends and Developments; Batley, R., Stoker, G., Eds.; Macmillan: London, UK, 1991; pp. 21-40.

27. Bache, I.; Bartle, I.; Flinders, M. Unravelling Multi-Level Governance: Beyond the Binary Divide; Workshop Governance and Participation Research: Sheffield, UK, 6 June 2012.

28. Lorvi, K. Unpacking administrative capacity for the management of structural funds in small and large municipalities: The Estonian Case. Adm. Cult. 2014, 14, 98-124.

29. Pierre, J.; Peters, B. Governance, Politics and the State; Palgrave Macmillan: Houndmills, UK, 2000.

30. Kauppi, N. Democracy, Social Resources and Political Power in the European Union; Manchester University Press: Manchester, $\mathrm{UK}, 2005$.

31. Kauppi, N. Elements for a Structural Constructivist Theory of Politics and of European Integration, Center for European Studies Working Paper Series, No. 104, Minda de Gunzburg Center for European Studies; Harvard University: Cambridge, MA, USA, 2002.

32. Hix, S. The Study of the European Union II: The new governance agenda and its rival. J. Eur. Public Policy 1998, 5, 38-65. [CrossRef]

33. Kauppi, N. EU Politics. In Sociology of the European Union; Favell, A., Guiradon, V., Eds.; Palgrave: Basingstoke, UK, 2011.

34. Newman, P.; Verpraet, G. The impacts of partnership on urban governance: Conclusions from recent European research. Reg. Stud. 1999, 33, 487-491. [CrossRef]

35. Pearce, G.; Ayres, S.; Tricker, M. Decentralisation and devolution to the English regions: Assessing the implications for rural policy and delivery. J. Rural Stud. 2005, 21, 197-212. [CrossRef]

36. Osti, G. LEADER and Partnerships: The case of Italy. Sociol. Rural. 2000, 40, 172-180. [CrossRef]

37. OECD Rural Policy Reviews. Scotland, UK; OECD Publishing: Paris, France, 2008.

38. OECD Rural Policy Reviews. England, UK; OECD Publishing: Paris, France, 2011.

39. OECD Rural Policy Reviews. Italy; OECD Publishing: Paris, France, 2009.

40. European Commission. The LEADER Approach: A Basic Guide; Office for Official Publications of the European Communities: Luxembourg, Belgium, 2006.

41. Kearney, B.; Boyle, G.E.; Walsh, J. EU LEADER I Initiative in Ireland: Evaluation and Recommendations; Department of Agriculture, Food and Forestry: Dublin, Ireland, 1994.

42. Ekosgen. National Impact Assessment of LEADER; The Story of LEADER in England, report commissioned by DEFRA; Ekosgen: Sheffield, UK, 2010.

43. Ekosgen. National Impact Assessment of LEADER; The LEADER Approach in the Devolved Nations, report commissioned by DEFRA; Ekosgen: Sheffield, UK, 2010.

44. Fargion, V.; Morlino, L.; Profeti, S.; Roux, C. Européanisation et représentation territoriales en Italie. Pole Sud 2006, 24, 99-120. [CrossRef]

45. Putnam, R.D.; Leonardi, R.; Nanetti, R.Y. Making Democracy Work, Civic Traditions in Modern Italy; Princeton University Press: Princeton, NJ, USA, 1994. 
46. Yin, R. Case Study Research, Design and Methods, 5th ed.; SAGE Publications: Los Angeles, CA, USA, 2014.

47. Department for Environment, Food and Rural Affairs. Rural Strategy 2004; DEFRA Publications: London, UK, 2004.

48. Brown, G. Rural Development and the LEADER Approach in the UK and Ireland; Carnegie UK Trust: Dunfermline, UK, 2010.

49. Scottish LEADER Coordinators, Scottish LEADER Programme 2007-2013; Dumfries \& Galloway LEADER Programme: New Abbey, UK, 2011.

50. Sabatier, P.A. An advocacy coalition framework of policy change and the role of policy-oriented learning therein. Policy Sci. 1988, 21, 129-168. [CrossRef]

51. Final Report 2007-2013: Ekosgen. Evaluation of the Argyll \& Islands. LEADER Programme; Report commissioned by the Argyll \& Islands LAG; Ekosgen: Sheffield, UK, 2013.

52. Argyll and the Islands LEADER Local Action Group. Local Development Strategy \& Business Plan 2007-2013; Argyll and the Islands LAG: Oban, UK, 2009.

53. Annual Report 2010-2011: Argyll and the Islands LEADER 2007-2013. Local Action Group; Argyll and the Islands LAG: Oban, $\mathrm{UK}, 2012$.

54. The Rural Development E Programmes Team LEADER Local Action Group Coast, Wolds, Wetlands E Waterways—Local Development Strategy; CWWW LAG: Driffield, UK, 2009.

55. Duggleby, N.; Butterworth, N. Rural Capacity Building Project-Evaluation Report; CWWW LAG: Driffield, UK, 2013.

56. Bolli, M.; Mantino, F.; Tarangioli, S. Country Profiles on Rural Characteristics: Italy, Assessing the Impact of Rural Development Policies (RuDI) Project (Work Package 1: Priorities in Rural Development Policies; Deliverable D 1.1.) Funded by the 7th Framework Programme for Research and Technology Development of the European Commission; INEA: Roma, Italy, 2008.

57. Ministero del Tesoro, Bilancio e Programmazione Economica Il Percorso di Riforma dei Fondi Strutturali 2000-2006; Istituto Poligrafico e Zecca dello Stato: Roma, Italy, 1999.

58. Ministero delle Politiche Agricole Alimentari e Forestali Piano Strategico Nazionale 2007-2013; MiPAAF: Roma, Italy, 2010.

59. Ministero dello Sviluppo Economico, Dipartimento per le Politiche di Sviluppo e Coesione Quadro Strategico Nazionale per la Politica Regionale di Sviluppo 2007-2013; MiSE: Roma, Italy, 2007.

60. Mantino, F. L'anomalia Nella PAC: Eterogeneità e Dinamiche del LEADER in Italia, Rete Nazionale per lo Sviluppo Rurale; INEA: Roma, Italy, 2009.

61. Granberg, L.; Andersson, K.; Kovách, I. Evaluating the European Approach to Rural Development. Grass-Roots Experiences of the LEADER Programme. Perspectives on Rural Policy and Planning; Ashgate: Surrey, UK, 2015.

62. OECD Linking Regions and Central Governments. Contracts for Regional Development; OECD Publishing: Paris, France, 2007.

63. Gruppo di Azione Locale Delta 2000. Piano di Azione Locale per il Delta Emiliano-Romagnolo 2007-2013; GAL Delta 2000: Ostellato, Italy, 2008.

64. Gigante, R.; Fava, A. Il Programma LEADER 2007-2013, Stato di Attuazione Dell'approccio LEADER e Percorsi Intrapresi dai GAL in Emilia-Romagna; Regione Emilia-Romagna: Bologna, Italy, 2012.

65. Gruppo di Azione Locale Delta 2000. Il PAL LEADER Asse 4 del Delta Emiliano-Romagnolo. PSR 2007-2013; Quaderno Finale. I Risultati Raggiunti; GAL Delta 2000: Ostellato, Italy, 2015.

66. Sivini, S. Nuovi Percorsi di Sviluppo Locale. Il Programma LEADER e la Sua Applicazione in due Aree del Mezzogiorno; Rubettino Editore: Catanzaro, Italy, 2003.

67. Gruppo di Azione Locale Capo Santa Maria di Leuca. Piano di Sviluppo Locale ‘Capo di Leuca 2015’; GAL C. S. M. di Leuca: Tricase, Italy, 2010.

68. Gruppo di Azione Locale del Capo di Santa Maria di Leuca. LEADER + Risultati e Interventi; Rapporto finale sull'attuazione del Programma Nella Terra dei Due Mari; GAL C.S.M. di Leuca: Tricase, Italy, 2009.

69. Jones, O.; Little, J. Rural challenge(s): Partnership and new rural governance. J. Rural Stud. 2000, 16, 171-183. [CrossRef]

70. Gray, B.; Wood, D.J. Collaborative alliances: Moving from practice to theory. J. Appl. Behav. Sci. 1991, 27, 3-22. [CrossRef]

71. The European Evaluation Helpdesk for Rural Development Guidelines. Evaluation of LEADER/CLLD; European CommissionDirectorate-General for Agriculture and Rural Development-Unit, C.4: Brussels, Belgium, 2017.

72. European Court of Auditors. Implementation of the Leader Approach for Rural Development; Special report, No. 5; Publications Office of the European Union: Luxembourg, 2010.

73. Moseley, M.J. Local Partnerships for Rural Development. The European Experience; CABI Publishing: Wallingford, UK, 2002.

74. Schucksmith, M. Disintegrated rural development? Neo-endogenous rural development, planning and place-Shaping in diffused power context. Sociol. Rural. 2010, 50, 1-14. [CrossRef]

75. High, C.; Nemes, G. Social learning in LEADER: Exogenous, endogenous and hybrid evaluation in rural development. Sociol. Rural. 2007, 47, 103-119. [CrossRef]

76. Thuesen, A.; Nielsen, N. Territorial perspective on EU's LEADER approach in Denmark: The added value of community-led local development of rural and coastal areas in a multi-level governance settings. Eur. Countrys. 2014, 6, 307-326. [CrossRef]

77. Buller, H. Re-creating rural territories: LEADER in France. Sociol. Rural. 2000, 40, 190-199. [CrossRef]

78. Hooghe, L. Cohesion Policy and European Integration: Building Multi-Level Governance; Oxford University Press: New York, NY, USA, 1996.

79. Yang, A.; Rounsevell, M.; Haggett, C.; Wilson, R. Recentralisation through regionalism in the implementation of rural development policy in Scotland. J. Environ. Plan. Manag. 2015, 58, 1666-1689. [CrossRef] 
80. Bolli, M.; Mantino, F.; Zanetti, B. The Use of LEADER Approach in Designing and Implementing Biodiversity and Water Resources Management (Cluster 6), Assessing the Impact of Rural Development Policies (Rudi) Project (Work Package 8: Delta 2000 Case Study) funded by the 7th Framework Programme for Research and Technology Development of the European Commission; INEA: Roma, Italy, 2008.

81. Garrod, G.; Liddon, A.; Phillipson, J.; Rowe, F.; Shortall, S.; Shucksmith, M. After Brexit: 10 Key Questions for Rural Policy; University of Newcastle upon Tyne, Center for Rural Economy: Newcastle Upon Tyne, UK, 2017. 